University of Nebraska - Lincoln

DigitalCommons@University of Nebraska - Lincoln

\title{
A cation exchange model to describe Cs+ sorption at high ionic strength in subsurface sediments at Hanford site, USA
}

Chongxuan Liu

Pacific Northwest National Laboratory, chongxuan.liu@pnl.gov

John M. Zachara

Pacific Northwest National Laboratory, john.zachara@pnl.gov

Steven Smith

Pacific Northwest National Laboratory, steven.smith@pnl.gov

Follow this and additional works at: https://digitalcommons.unl.edu/usdoepub

Part of the Bioresource and Agricultural Engineering Commons

Liu, Chongxuan; Zachara, John M.; and Smith, Steven, "A cation exchange model to describe Cs+ sorption at high ionic strength in subsurface sediments at Hanford site, USA" (2004). US Department of Energy Publications. 272.

https://digitalcommons.unl.edu/usdoepub/272

This Article is brought to you for free and open access by the U.S. Department of Energy at DigitalCommons@University of Nebraska - Lincoln. It has been accepted for inclusion in US Department of Energy Publications by an authorized administrator of DigitalCommons@University of Nebraska - Lincoln. 


\title{
A cation exchange model to describe $\mathrm{Cs}^{+}$sorption at high ionic strength in subsurface sediments at Hanford site, USA
}

\author{
Chongxuan Liu*, John M. Zachara, Steve C. Smith \\ Environmental Dynamics/Simulation, Pacific Northwest National Laboratory, \\ P.O. Box 999, MSIN K8-96, Richland, WA 99352, USA
}

Received 10 June 2002; received in revised form 20 June 2003; accepted 20 June 2003

\begin{abstract}
A theoretical and experimental study of cation exchange in high ionic strength electrolytes was performed using pristine subsurface sediments from the U.S. Department of Energy Hanford site. These sediments are representative of the site contaminated sediments impacted by release of high level waste (HLW) solutions containing ${ }^{137} \mathrm{Cs}^{+}$in $\mathrm{NaNO}_{3}$ brine. The binary exchange behavior of $\mathrm{Cs}^{+}-\mathrm{Na}^{+}, \mathrm{Cs}^{+}-\mathrm{K}^{+}$, and $\mathrm{Na}^{+}-\mathrm{K}^{+}$was measured over a range in electrolyte concentration. Vanselow selectivity coefficients $\left(K_{\mathrm{v}}\right)$ that were calculated from the experimental data using Pitzer model ion activity corrections for aqueous species showed monotonic increases with increasing electrolyte concentrations. The influence of electrolyte concentration was greater on the exchange of $\mathrm{Na}^{+}-\mathrm{Cs}^{+}$ than $\mathrm{K}^{+}-\mathrm{Cs}^{+}$, an observation consistent with the differences in ion hydration energy of the exchanging cations. A previously developed two-site ion exchange model [Geochimica et Cosmochimica Acta 66 (2002) 193] was modified to include solvent (water) activity changes in the exchanger phase through application of the Gibbs-Duhem equation. This water activity-corrected model well described the ionic strength effect on binary $\mathrm{Cs}^{+}$exchange, and was extended to the ternary exchange system of $\mathrm{Cs}^{+}-\mathrm{Na}^{+}-\mathrm{K}^{+}$on the pristine sediment. The model was also used to predict ${ }^{137} \mathrm{Cs}^{+}$distribution between sediment and aqueous phase $\left(K_{\mathrm{d}}\right)$ beneath a leaked HLW tank in Hanfordd's S-SX tank using the analytical aqueous data from the field and the binary ion exchange coefficients for the pristine sediment. The $K_{\mathrm{d}}$ predictions closely followed the trend in the field data and were improved by consideration of water activity effects that were considerable in certain regions of the vadose zone plume.
\end{abstract}

(C) 2003 Elsevier B.V. All rights reserved.

Keywords: Sorption; Cesium; Ion exchange; Ionic strength; Water activity; Contamination

* Corresponding author. Tel.: +1-509-376-0129; fax: +1-509-376-3650.

E-mail address: chongxuan.liu@pnl.gov (C. Liu). 


\section{Introduction}

The cation exchange of $\mathrm{Cs}^{+}$to layer silicates and soils is typically represented by a mass action equation of the following form (Bradbury and Baeyens, 2000; Brouwer et al., 1983; Comans et al., 1991; Cornell, 1993; Cremers et al., 1988; Eberl, 1980; Poinssot et al., 1999; Zachara et al., 2002):

$$
\mathrm{uCs}_{(\mathrm{aq})}^{+}+\mathrm{AX}_{\mathrm{u}}=\mathrm{uCsX}+\mathrm{A}_{(\mathrm{aq})}^{\mathrm{u}+}
$$

where $\mathrm{u}$ is the valence of ionic species $\mathrm{A} ; \mathrm{AX}_{\mathrm{u}}$ and $\mathrm{CsX}$ are the exchanger phase species of $\mathrm{A}^{\mathrm{u}+}$ and $\mathrm{Cs}^{+}$; and $\mathrm{Cs}^{+}$and $\mathrm{A}^{\mathrm{u}+}$ are aqueous species. The equilibrium exchange constant $\left(K_{\mathrm{ex}}\right)$ for reaction $(1)$ is defined as:

$$
K_{\mathrm{ex}}=\left(a_{\mathrm{CsX}}^{\mathrm{u}} / a_{\mathrm{AX}_{\mathrm{u}}}\right)\left(a_{\mathrm{A}^{\mathrm{u}+}} / a_{\mathrm{Cs}^{+}}^{\mathrm{u}}\right)
$$

where $a_{\mathrm{i}}$ represents the activity of species $\mathrm{i}$. It is also convenient to define a Vanselow selectivity coefficient $\left(K_{\mathrm{v}}\right)$ :

$$
K_{\mathrm{v}}=\left(N_{\mathrm{Cs}}^{\mathrm{u}} / N_{\mathrm{A}}\right)\left(a_{\mathrm{A}^{\mathrm{u}+}} / a_{C s^{+}}^{\mathrm{u}}\right)
$$

where $N_{\mathrm{Cs}}$ and $N_{\mathrm{A}}$ are the mole fractions of exchanger phase species $\mathrm{Cs}^{+}$and $\mathrm{A}^{\mathrm{u}+}$. The $N_{\mathrm{i}}$ is defined to be,

$$
N_{i}=n_{i} / \sum_{j=1}^{M} n_{j} \quad i=1,2, \ldots, M
$$

where $n_{\mathrm{i}}$ is the mole number of cation species $\mathrm{i}$ and $M$ is the number of cation species in the exchanger phase. The mole fraction and activity of species $i$ in the exchanger phase is related by a rational activity coefficient,

$$
f_{i}=a_{i} / N_{i}
$$

The $K_{\mathrm{v}}$ equals $K_{\mathrm{ex}}$ if the exchange is ideal (i.e., $f_{\mathrm{i}}=1, i=1,2, \ldots M$ ). The experimental $K_{\mathrm{v}}$ is computed from the experimentally measurable conditional constant $\left(K_{\mathrm{c}}\right)$ corrected for aqueous activity. The conditional constant is typically defined as:

$$
K_{\mathrm{c}}=\left(N_{\mathrm{Cs}}^{\mathrm{u}} / N_{\mathrm{A}}\right)\left(C_{\mathrm{A}^{\mathrm{u}+}} / C_{\mathrm{Cs}^{+}}^{\mathrm{u}}\right)
$$

where $C_{\mathrm{i}}$ represents aqueous concentration of species $\mathrm{i}$.

Cesium adsorption by layer silicates and the phyllosilicate fraction of soils and sediments has often been described as a cation exchange process on two or more sites with distinctly different selectivity (Bradbury and Baeyens, 2000; Brouwer et al., 1983; Cremers et al., 1988; Poinssot et al., 1999; Zachara et al., 2002). Generally, the high affinity sites are believed to reside along the weathered periphery of $1.0 \mathrm{~nm}$ micas and illites (Cornell, 1993; Cremers et al., 1988; Sawhney, 1972), while lower selectivity sites are contributed by the basal and interlamellar regions of expansible (smectites) and partially expansible (vermiculites) layer silicates. Multiple site adsorption models em- 
bodying mass action relationships on these distinct ion exchange sites have provided reasonable simulations of the effects of $\mathrm{Cs}^{+}$and electrolyte concentration on $\mathrm{Cs}^{+}$sorption (Bradbury and Baeyens, 2000; Brouwer et al., 1983; Cremers et al., 1988; Poinssot et al., 1999; Zachara et al., 2002).

The underlying assumption in the multiple-site $\mathrm{Cs}^{+}$adsorption models has been that the exchange process on each site is ideal. When an exchange process is ideal, the solid phase activities equal their mole fractions on the exchanger, and Vanselow selectivity coefficient equals the exchange constant, i.e., $K_{\mathrm{v}}=K_{\mathrm{ex}}$. Vanselow selectivity coefficients for $\mathrm{Cs}^{+}$ exchange on illite and sediment, however, have been observed to vary by factors of 10 or more (Brouwer et al., 1983; Zachara et al., 2002) with changing electrolyte concentration indicating exchange nonideality. The nonideality may result from the inadequate consideration of aqueous phase complexation and ion association, or from phenomena associated with the exchanger phase such as sorption site heterogeneity, cation demixing (segregation), or interlayer swelling/contraction resulting from changes in water activity (Fletcher and Townsend, 1981; Grant and Fletcher, 1993). The nonideality resulting from inadequate consideration in aqueous phase was typically corrected using more accurate aqueous speciation and ion-ion interaction model, such as Pitzer model (Pitzer, 1994). The nonideal behavior associated with the exchanger phase may be described with thermodynamic excess Gibbs-free energy functions (e.g. Elprince and Babcock, 1975; Grant and Fletcher, 1993; Sposito, 1981; Wilson, 1964).

Previously, we have identified the mineralogic residence of high and low affinity $\mathrm{Cs}^{+}$exchange sites in uncontaminated subsurface sediment from the U.S. DOE Hanford site, and modeled $\mathrm{Cs}^{+}-\mathrm{Na}^{+}$and $\mathrm{Cs}^{+}-\mathrm{K}^{+}$adsorption to the sediment using a two-site model under the ideal exchange assumption (Zachara et al., 2002). The ratio of solution phase activity coefficients (e.g., $\gamma \mathrm{Cs}^{+} / \gamma \mathrm{Na}^{+}$or $\gamma \mathrm{Cs}^{+} / \gamma \mathrm{K}^{+}$) was approximated as unity, based on the Debye-Huckel equation for the homovalent exchanging ions, and the ratio of exchanger phase activity coefficients (e.g., $f_{\mathrm{Cs}} / f_{\mathrm{Na}}$ or $f_{\mathrm{Cs}} / f_{\mathrm{K}}$ ) was also assumed to be unity. However, after including the effects of ion-ion interaction in the aqueous phase using the Pitzer model (Pitzer, 1994), the Vanselow selectivity coefficients for $\mathrm{Cs}^{+}-\mathrm{Na}^{+}$and $\mathrm{Cs}^{+}-\mathrm{K}^{+}$exchanges showed a monotonic increase with increasing electrolyte concentration, indicating that the $\mathrm{Cs}$ exchanges are nonideal in the exchanger phase. This paper describes the influence of electrolyte concentration on the nonideality in the exchanger phase as a water activity effect, and incorporates water activity into a multi-site $\mathrm{Cs}^{+}$adsorption/exchange model. This "water activity-corrected" model is shown to yield improved predictions of ${ }^{137} \mathrm{Cs}^{+}$distribution beneath a leaked HLW waste tank at Hanford where the discharged waste solution was a ${ }^{137} \mathrm{Cs}^{+}$containing $\mathrm{NaNO}_{3}$ brine.

\section{Theory}

For a binary cation exchange reaction of $\mathrm{B}^{\mathrm{v}+}$ replacing $\mathrm{A}^{\mathrm{u}+}$ in the exchanger, the relationship between $K_{\mathrm{v}}$ and $K_{\mathrm{ex}}$ may be written as,

$$
K_{\mathrm{v}}=K_{\mathrm{ex}} f_{\mathrm{A}}^{\mathrm{v}} / f_{\mathrm{B}}^{\mathrm{u}}
$$


The differential form of the natural logarithm of Eq. (7) may be stated as:

$$
\mathrm{d} \ln K_{\mathrm{v}}=v \mathrm{~d} \ln f_{\mathrm{A}}-u \mathrm{~d} \ln f_{\mathrm{B}}
$$

Note that $K_{\text {ex }}$ is a constant. The Gibbs-Duhem equation for the exchanger is given by (Grant and Fletcher, 1993; Sposito, 1981):

$$
N_{\mathrm{A}} \mathrm{d} \ln \left(f_{\mathrm{A}} N_{\mathrm{A}}\right)+N_{\mathrm{B}} \mathrm{d} \ln \left(f_{\mathrm{B}} N_{\mathrm{B}}\right)+n_{\mathrm{w}}^{\prime} \mathrm{d} \ln a_{\mathrm{w}}=0
$$

where $n_{\mathrm{w}}^{\prime}$ is the ratio of number of moles of water versus total moles of cations in the exchanger phase; and $a_{\mathrm{w}}$ is the water activity in the exchanger. For a binary system, $N_{\mathrm{A}}+N_{\mathrm{B}}=1$. The combination of Eqs. (8) and (9) leads to the expressions (Grant and Fletcher, 1993; Sposito, 1981):

$$
\begin{aligned}
& u \mathrm{~d} \ln f_{\mathrm{B}}+\mathrm{d}\left(\left(1-E_{\mathrm{B}}\right) \ln K_{\mathrm{v}}\right)=-\ln K_{\mathrm{v}} \mathrm{d} E_{\mathrm{B}}-u v n_{\mathrm{w}} \mathrm{d} \ln a_{\mathrm{w}} \\
& v \mathrm{~d} \ln f_{\mathrm{A}}-\mathrm{d}\left(E_{\mathrm{B}} \ln K_{\mathrm{v}}\right)=-\ln K_{\mathrm{v}} \mathrm{d} E_{\mathrm{B}}-u v n_{\mathrm{w}} \mathrm{d} \ln a_{\mathrm{w}}
\end{aligned}
$$

where $E_{\mathrm{B}}$ and $n_{\mathrm{w}}$ are the equivalents of $\mathrm{BX}_{\mathrm{v}}$ and the number of moles of water in the exchanger, divided by the total equivalents of cation exchange capacity (CEC), respectively. The left hand sides of Eqs. (10) and (11) are exact differential, so must be the right hand sides. A necessary mathematical condition for the right hand side to be an exact differential is:

$$
\left(\frac{\partial \ln K_{\mathrm{v}}}{\partial \ln a_{\mathrm{w}}}\right)_{E_{\mathrm{B}}}=u v\left(\frac{\partial n_{\mathrm{w}}}{\partial E_{\mathrm{B}}}\right)_{a_{\mathrm{w}}}
$$

Eq. (12) indicates that $\ln K_{\mathrm{v}}$ and $n_{\mathrm{w}}$ are functions of water activity $\left(\ln a_{\mathrm{w}}\right)$ and chemical composition $\left(E_{\mathrm{B}}\right)$. Generally, these functions have to be determined experimentally. Once $K_{\mathrm{v}}$ and $n_{\mathrm{w}}$ are known as functions of water activity and chemical composition, Eqs. (10) and (11) can be used to evaluate the rational activity coefficients. The most common approach used to evaluate the rational activity coefficients is to integrate Eqs. (10) and (11) in two steps from the Reference State to a state at which the experiment was performed (e.g.,Grant and Fletcher, 1993; Sposito, 1981). Note that integration of an exact differential equation (e.g., Eq. (10) or Eq. (11)) is independent of integration paths. The Reference State for a cation exchange species (e.g., $\mathrm{AX}_{\mathrm{u}}$ or $\mathrm{BX}_{\mathrm{v}}$ ) is defined as the homoionic form of the exchanger at equilibrium with an infinitely dilute aqueous solution of the exchanging cation (e.g., $\mathrm{B}^{\mathrm{v}+}$ or $\mathrm{A}^{\mathrm{u}+}$ ) at $298.15 \mathrm{~K}$ and 1 atm pressure (Gaines and Thomas, 1953) (Fig. 1). At this reference state, the activities of both cation and water in the exchanger phase are defined to be unity (Gaines and Thomas, 1953). From this definition, the reference state of water activity is the same in the aqueous and exchanger phase. We assume that there are no temperature and pressure changes during following analysis. Under this condition, the equilibrium water activity will be the same between aqueous and exchanger phases. We will, therefore, make no difference of water activity in aqueous and exchanger phases in following analysis.

The first integration step starts from the Reference State to a state characterized by: (i) unit mole fraction of the exchanger component of interest (e.g., homoionic exchanger $\mathrm{BX}_{\mathrm{v}}$ 


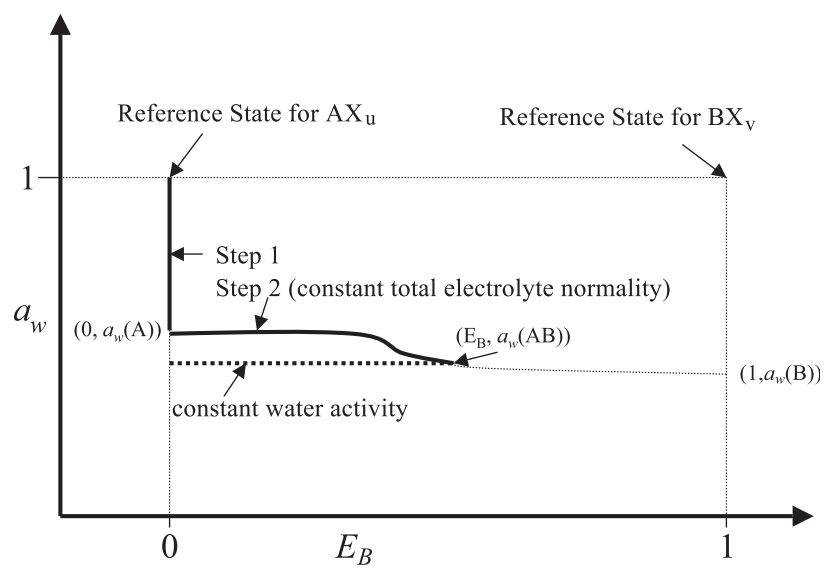

Fig. 1. A conceptual model showing the Reference States for adsorbed species in the exchanger and integral paths to estimate activity coefficients of the exchange species $\mathrm{AX}_{\mathrm{u}}$.

or $\mathrm{AX}_{\mathrm{u}}$ ), and (ii) a water activity corresponding to the total electrolyte normality at which the experiment is performed (Fig. 1). Specifically, in this step, Eq. (10) is integrated with $\ln a_{\mathrm{w}}$ from 0 to $\ln a_{\mathrm{w}}(\mathrm{B})$ at a fixed $E_{\mathrm{B}}=1$ and Eq. (11) is integrated with $\ln a_{\mathrm{w}}$ from 0 to $\ln$ $a_{\mathrm{w}}(A)$ at a fixed $E_{\mathrm{B}}=0 . a_{\mathrm{w}}(A)$ and $a_{\mathrm{w}}(B)$ are the water activities in the homoionic exchangers $\mathrm{AX}_{\mathrm{u}}$ and $\mathrm{BX}_{\mathrm{v}}$, respectively, at the total electrolyte normality at which the experiment is performed. The second step integrates from the final state of step 1 to a state characterized by the chosen exchanger composition $\left(E_{\mathrm{B}}\right)$ along a line with a constant total normality of electrolyte concentration (Fig. 1).

These two-step integration scheme yields the following relationships:

$$
\begin{aligned}
u \ln f_{\mathrm{B}}+\left(1-E_{\mathrm{B}}\right) \ln K_{\mathrm{v}}= & -\int_{\left(1, \ln a_{\mathrm{w}}(B)\right)}^{\left(E_{\mathrm{B}}, \ln a_{\mathrm{w}}(\mathrm{AB})\right)} \ln K_{\mathrm{v}}\left(E_{\mathrm{B}}^{\prime}, \ln a_{\mathrm{W}}^{\prime}\right) \mathrm{d} E_{\mathrm{B}}^{\prime} \\
& -u v\left[\int_{0}^{\ln a_{\mathrm{w}}(B)} n_{\mathrm{w}}\left(E_{\mathrm{B}}=1, \ln a_{\mathrm{W}}^{\prime}\right) \mathrm{d} \ln a_{\mathrm{W}}^{\prime}\right. \\
& \left.+\int_{\left(1, \ln a_{\mathrm{w}}(B)\right)}^{\left(E_{\mathrm{B}}, \ln a_{\mathrm{w}}(\mathrm{AB})\right)} n_{w}\left(E_{\mathrm{B}}^{\prime}, \ln a_{\mathrm{W}}^{\prime}\right) \mathrm{d} \ln a_{\mathrm{w}}^{\prime}\right] \\
v \ln f_{\mathrm{A}}-E_{\mathrm{B}} \ln K_{\mathrm{v}}=- & \int_{\left(0, \ln a_{\mathrm{w}}(A)\right)}^{\left(E_{\mathrm{B}}, \ln a_{\mathrm{w}}(\mathrm{AB})\right)} \ln K_{\mathrm{v}}\left(E_{\mathrm{B}}^{\prime}, \ln a_{\mathrm{W}}^{\prime}\right) \mathrm{d} E_{\mathrm{B}}^{\prime} \\
& -u v\left[\int_{0}^{\ln a_{\mathrm{w}}(A)} n_{\mathrm{w}}\left(E_{\mathrm{B}}=0, \ln a_{\mathrm{w}}^{\prime}\right) \mathrm{d} \ln a_{\mathrm{w}}^{\prime}\right. \\
& \left.+\int_{\left(0, \ln a_{\mathrm{w}}(A)\right)}^{\left(E_{\mathrm{B}}, \ln a_{\mathrm{w}}(\mathrm{AB})\right)} n_{w}\left(E_{\mathrm{B}}^{\prime}, \ln a_{\mathrm{w}}^{\prime}\right) \mathrm{d} \ln a_{\mathrm{w}}^{\prime}\right]
\end{aligned}
$$


where $E_{\mathrm{B}}^{\prime}$ and $\ln a_{\mathrm{w}}^{\prime}$ are the dummy variables for equivalent fraction of $\mathrm{BX}$ and natural logarithm of water activity, respectively. Combining Eqs. (7), (13), and (14), one obtains,

$$
\begin{aligned}
\ln K_{\mathrm{ex}}= & \int_{\left(0, \ln a_{\mathrm{w}}(A)\right)}^{\left(1, \ln a_{\mathrm{w}}(B)\right)} \ln K_{\mathrm{v}}\left(E_{\mathrm{B}}^{\prime}, \ln a_{\mathrm{w}}^{\prime}\right) \mathrm{d} E_{\mathrm{B}}^{\prime} \\
& +u v \int_{0}^{\ln a_{\mathrm{w}}(A)} n_{\mathrm{w}}\left(E_{\mathrm{B}}=0, \ln a_{\mathrm{w}}^{\prime}\right) \mathrm{d} \ln a_{\mathrm{w}}^{\prime} \\
& -u v \int_{0}^{\ln a_{\mathrm{w}}(B)} n_{\mathrm{w}}\left(E_{\mathrm{B}}=1, \ln a_{\mathrm{w}}^{\prime}\right) \mathrm{d} \ln a_{\mathrm{w}}^{\prime} \\
& +u v \int_{\left(0, \ln a_{\mathrm{w}}(A)\right)}^{\left(1, \ln a_{\mathrm{w}}(B)\right)} n_{\mathrm{w}}\left(E_{\mathrm{B}}^{\prime}, \ln a_{\mathrm{w}}^{\prime}\right) \mathrm{d} \ln a_{\mathrm{w}}^{\prime}
\end{aligned}
$$

Note that the first integrals on the right hand sides of Eqs. (15)-(17) were written differently from those in (Grant and Fletcher, 1993; Sposito, 1981; Gaines and Thomas, 1953) where water activity was not included in the two end states of the integral. Water activity was included here to emphasize its effects on the value of the integral. The effects of variable $n_{\mathrm{w}}$ on the integral values in Eqs. (13)-(15) are usually neglected (Sposito, 1981) due to the difficulty in its measurement and the fact that the terms related to $n_{\mathrm{w}}$ for $K_{\mathrm{ex}}$ evaluation (last three terms in the right hand side of Eq. (15)) often mutually cancel (Barrer and Klinowski, 1974). However, the individual rational activity coefficients [Eq. (13) or Eq. (14)] may be significantly affected by the water content terms [last two terms in the right hand side of Eq. (13) or Eq. (14)] (Barrer and Klinowski, 1974).

In the current case of $\mathrm{Cs}^{+}$exchange, the water content terms will be shown to be important in that the changes of $K_{\mathrm{v}}$ with electrolyte concentration parallel changes in water activity. In order to evaluate the integrals in Eqs. (13)-(15), one has to find the relationship between water activity and $E_{\mathrm{B}}$ at the normality at which the experiment was performed. This point becomes apparent if one draws the integral path for step 2 (Solid line in Fig. 1) used to obtain the rational activity coefficient $f_{\mathrm{A}}$. Fig. 1 shows that the integral step 2 is generally not a straight line from $E_{\mathrm{B}}=0$ to $E_{\mathrm{B}}$ under a constant electrolyte normality.

Here, we utilized an alternative integral path (short dashed line in Fig. 1) for Eqs. (10) and (11), that follows a constant water activity line from a state characterized by unit mole fraction of the exchanger component of interest, to the chosen exchange composition. Using this integral path, we obtained the following alternative integral expressions:

$$
\begin{aligned}
& u \ln f_{\mathrm{B}}-u \ln f_{\mathrm{B}}^{\mathrm{p}}\left(\ln a_{\mathrm{w}}\right)=-\left(1-E_{\mathrm{B}}\right) \ln K_{\mathrm{v}}\left(E_{\mathrm{B}}, \ln a_{\mathrm{w}}\right)-\int_{1}^{E_{\mathrm{B}}} \ln K_{\mathrm{v}}\left(E_{\mathrm{B}}^{\prime}, \ln a_{\mathrm{W}}\right) \mathrm{d} E_{\mathrm{B}}^{\prime} \\
& v \ln f_{\mathrm{A}}-v \ln f_{\mathrm{A}}^{\mathrm{p}}\left(\ln a_{\mathrm{w}}\right)=E_{\mathrm{B}} \ln K_{\mathrm{v}}\left(E_{\mathrm{B}}, \ln a_{\mathrm{w}}\right)-\int_{0}^{E_{\mathrm{B}}} \ln K_{\mathrm{v}}\left(E_{\mathrm{B}}^{\prime}, \ln a_{\mathrm{w}}\right) \mathrm{d} E_{\mathrm{B}}^{\prime}
\end{aligned}
$$




$$
\ln K_{\mathrm{ex}}=\int_{0}^{1} \ln K_{\mathrm{v}}\left(E_{\mathrm{B}}^{\prime}, \ln a_{\mathrm{w}}\right) \mathrm{d} E_{\mathrm{B}}^{\prime}+\ln \left(\left(f_{\mathrm{B}}^{\mathrm{p}}\left(\ln a_{\mathrm{w}}\right)\right)^{\mathrm{u}} /\left(f_{\mathrm{A}}^{\mathrm{p}}\left(\ln a_{\mathrm{w}}\right)\right)^{\mathrm{v}}\right)
$$

where $f_{\mathrm{B}}^{\mathrm{p}}\left(\ln a_{\mathrm{w}}\right)$ and $f_{\mathrm{A}}^{\mathrm{p}}\left(\ln a_{\mathrm{w}}\right)$ are activity coefficients for the homoionic $\mathrm{BX}_{\mathrm{v}}$ and $\mathrm{AX}_{\mathrm{u}}$ exchangers at the water activity of $a_{\mathrm{w}}$, respectively.

Compared with Eqs. (13)-(15), the current approach can avoid: (i) measuring the water content in the exchanger as a function of water activity in the mixed electrolyte, and (ii) evaluating the relationship between water activity and $E_{\mathrm{B}}$. The $K_{\mathrm{v}}$ can be estimated as a function of $E_{\mathrm{B}}$ and $\ln a_{\mathrm{w}}$ from exchange experiments with variable ionic strength (or water activity). However, in choosing a functional form of $K_{\mathrm{v}}$ to fit experimental data, Eq. (18) serves as a constraint to the water activity contribution to $K_{\mathrm{v}}$ because $K_{\text {ex }}$ must be a constant. In other words, the $K_{\mathrm{v}}$ determined from experimental data as a function of composition and water activity in the exchanger contains the information of $\left(f_{\mathrm{B}}^{\mathrm{p}}\left(\ln a_{\mathrm{w}}\right)\right)^{\mathrm{u}} /$ $\left(f_{\mathrm{A}}^{\mathrm{p}}\left(\ln a_{\mathrm{w}}\right)\right)^{\mathrm{v}}$. Alternatively, one can experimentally evaluate the activity coefficients independently, $f_{\mathrm{B}}^{\mathrm{p}}\left(\ln a_{\mathrm{w}}\right)$ and $f_{\mathrm{A}}^{\mathrm{p}}\left(\ln a_{\mathrm{w}}\right)$, using the following formula:

$$
\begin{aligned}
& u \ln f_{\mathrm{B}}^{\mathrm{p}}\left(\ln a_{\mathrm{w}}\right)=-u v \int_{0}^{\ln a_{\mathrm{w}}} n_{\mathrm{w}}^{\mathrm{B}}\left(\ln a_{\mathrm{w}}^{\prime}\right) \operatorname{d} \ln a_{\mathrm{w}}^{\prime} \quad\left(E_{\mathrm{B}}=1\right) \\
& v \ln f_{\mathrm{A}}^{\mathrm{p}}\left(\ln a_{\mathrm{w}}\right)=-u v \int_{0}^{\ln a_{\mathrm{w}}} n_{\mathrm{w}}^{\mathrm{A}}\left(\ln a_{\mathrm{w}}^{\prime}\right) \mathrm{d} \ln a_{\mathrm{w}}^{\prime} \quad\left(E_{\mathrm{B}}=0\right)
\end{aligned}
$$

where $n_{\mathrm{w}}^{\mathrm{B}}$ or $n_{\mathrm{w}}^{\mathrm{A}}$ denotes the number of moles of water per equivalent exchange capacity in the homoionic exchanger of $\mathrm{BX}_{\mathrm{v}}$ or $\mathrm{AX}_{\mathrm{u}}$. Eqs. (19) and (20) were derived by integrating Eqs. (10) and (11) along a pure $\mathrm{BX}_{\mathrm{v}}$ or $\mathrm{AX}_{\mathrm{u}}$ line from the Reference State to a water activity of interest.

Although Eqs. (16)-(20) were derived for the overall exchange of B for A, these relationships also hold for mass action on individual sites as long as there is no interaction energy between them. We define "site" as a homogeneous group of exchange locations where the sorbate-sorbent interaction energy is the same under constant water activity (e.g., the high and low affinity sites used in past $\mathrm{Cs}^{+}$adsorption modeling). According to this definition, nonideal behavior at an individual site can only be caused by ion hydration effects as a function of water activity because $K_{\mathrm{v}}$ at individual site will be only a function of water activity $\left(\ln a_{\mathrm{w}}\right)$, but not a cation fraction $\left(E_{\mathrm{B}}\right)$ in the exchanger phase.

\section{Materials and methods}

\subsection{Sediment recovery and preparation}

The collection, preparation, and processing methods for the subsurface sediment used in this study were detailed in Zachara et al. (2002). Briefly, a sample of uncontaminated Hanford sediment representative of the $10 \mathrm{~m}$ below leaked tanks in the S-SX tank farm (termed as the 'Above B' composite) was made by compositing core samples from monitoring wells surrounding the S-SX tank farm. The sediments were air-dried and 
sieved to remove the $>2 \mathrm{~mm}$ fraction and homogenized. The sediments were treated with 1 mol/1 sodium acetate $(\mathrm{NaOAc})$ at $\mathrm{pH} 5.0$ (with acetic acid) to remove carbonates and soluble salts. The mineralogy of untreated sediments was determined by optical and X-ray diffraction analysis. The cation exchange capacity (CEC) of the treated homoionic sediments was measured in $\mathrm{Na}^{+}$and $\mathrm{K}^{+}$electrolytes. The CEC varied by a factor of approximately 2 in the different electrolytes. In the following analysis, the CEC determined in $\mathrm{K}^{+}$electrolyte $\left(8.25 \times 10^{-5}\right.$ equivalent/g) was used as the total site concentration. The CEC determined in $\mathrm{K}^{+}$electrolyte was larger than measured in $\mathrm{Na}^{+}$ electrolyte.

\subsection{Binary exchange}

Binary ion exchange experiments of $\mathrm{Cs}-\mathrm{Na}$ and $\mathrm{Cs}-\mathrm{K}$ were previously preformed with a wide range of $\mathrm{Cs}^{+}$concentrations on homoionic $\mathrm{Na}^{+}$and $\mathrm{K}^{+}$sediments, yielding experimental $K_{\mathrm{c}}$ functions versus mole or equivalent fraction occupation of the exchanger by $\mathrm{Cs}^{+}$(Zachara et al., 2002). However, the previous analyses of $\mathrm{Cs}^{+}$exchange on Hanford sediment relied on the use of a conditional equilibrium constant $\left(K_{\mathrm{c}}\right)$ where concentration terms, rather than activities, were used in the equilibrium quotient. We rationalized this approach for homovalent exchange (e.g., $\mathrm{Cs}^{+}$for $\mathrm{Na}^{+}$, and $\mathrm{Cs}^{+}$for $\mathrm{K}^{+}$) by suggesting that the ratio of activity coefficients: $\gamma \mathrm{Cs}^{+} / \gamma \mathrm{Na}^{+}$or $\gamma \mathrm{Cs}^{+} / \gamma \mathrm{K}^{+} \approx 1$ under the used experimental conditions. Because the electrolyte concentrations used in those experiments were quite high (up to $5 \mathrm{~mol} / \mathrm{I} \mathrm{NaNO}_{3}$ and $1 \mathrm{~mol} / \mathrm{KNO}_{3}$ ), the activities of aqueous species were recalculated here using the Pitzer ion-ion interaction model (Pitzer, 1994). These activities for $\mathrm{Cs}^{+}$and the electrolyte ions $\left(\mathrm{Na}^{+}\right.$and $\left.\mathrm{K}^{+}\right)$were used in the recalculation of Vanselow selectivity coefficients $\left(K_{\mathrm{v}}\right)$ that are reported here.

New experiments of the ion exchange between $\mathrm{K}^{+}$and $\mathrm{Na}^{+}$were performed on the Hanford sediment in both $\mathrm{NaNO}_{3}$ and $\mathrm{KNO}_{3}$ electrolytes under conditions similar to those in Zachara et al. (2002). Potassium adsorption was determined on the NaOAc-treated 'Above B' sediment in three electrolyte solutions: 1.0, 0.1 and $0.01 \mathrm{~mol} / 1 \mathrm{NaNO}_{3}$. The $\mathrm{Na}^{+}$-saturated sediment, $\mathrm{KNO}_{3}$ spike, and $\mathrm{NaNO}_{3}$ electrolyte were equilibrated overnight $(\sim 16 \mathrm{~h})$ in Oakridge polycarbonate tubes in a controlled environmental shaker at $30{ }^{\circ} \mathrm{C}$ and $70 \mathrm{rpm}$. After equilibration, the suspensions were filtered $(0.2 \mu \mathrm{m})$ into a polystyrene tube for analysis after discarding the first 15 drops of filtrate. The potassium was measured by inductively coupled plasma atomic emission spectroscopy (ICP-AES).

Sodium adsorption on $\mathrm{K}^{+}$-saturated sediment was evaluated in three electrolyte solutions: $1,0.1$ and $0.01 \mathrm{~mol} / \mathrm{KNO}_{3}$. The NaOAc-extracted 'Above B' sediment was saturated with $\mathrm{K}^{+}$by placing $50 \mathrm{~g}$ of the sediment in SpectraPorR 7 dialysis tubing with $100 \mathrm{ml}$ of $0.1 \mathrm{~mol} / 1 \mathrm{KNO}_{3}$ and dialyzed against 3.51 of $0.1 \mathrm{~mol} / \mathrm{KNO}_{3}$. The sediment was dialyzed for 5 days with daily replacements of the $\mathrm{KNO}_{3}$ solution, and then for 7 days with daily replacements of deionized water. The sediment was transferred to a plastic jar and dried at $35{ }^{\circ} \mathrm{C}$. The $\mathrm{K}^{+}$-treated sediment, $\mathrm{NaNO}_{3}$ spike solution, and $\mathrm{KNO}_{3}$ electrolyte were equilibrated under the same conditions as in $\mathrm{K}^{+}$adsorption experiments. The $\mathrm{Na}^{+}$ adsorption was monitored by measuring ${ }^{22} \mathrm{Na}$ (NEN Life Science Products; Boston, MA), which was added in the $\mathrm{NaNO}_{3}$ spike solution $(500-833 \mathrm{~Bq} / \mathrm{ml})$. Following equilibration, the suspensions were filtered $(0.2 \mu \mathrm{m})$ and collected into subsamples after discarding the 
first 15 drops of filtrate. One subsample was collected in a tared plastic gamma-count tube, and the other in a polystyrene tube for ICP-AES analysis of $\left[\mathrm{Na}^{+}\right]$and $\left[\mathrm{K}^{+}\right]$. The gamma count tube was re-weighed to determine the sample mass. The ${ }^{22} \mathrm{Na}$-activity in the filtrate was determined using a Wallac gamma counter (model 1480) with an 80-mm NaI crystal detector.

\subsection{Binary data analysis}

Aqueous speciation, activity coefficients, and water activity in the aqueous phase were calculated for each exchange sample in Zachara et al. (2002), and in the $\mathrm{Na}^{+}$and $\mathrm{K}^{+}$ exchange experiments performed here, using measured aqueous concentrations and a computerized chemical equilibrium program, GMIN (Felmy, 1995), which incorporated the Pitzer model (Pitzer, 1994). The binary and mixed Pitzer parameters for the $\mathrm{Cs}^{+}, \mathrm{Na}^{+}$, and $\mathrm{K}^{+}$system used in the database are summarized in Table 1. GMIN uses a free energy minimization approach (Felmy, 1995) and the free energy of formation of the species used in the calculation are also included in Table 1. As mentioned before, the water activity is the same in exchanger and aqueous phases at equilibrium based on the definition of the exchanger Reference State. The water activity calculated from aqueous speciation model was, therefore, directly used for the exchanger phase in the following analysis.

\subsection{Recovery and analysis of Cs-contaminated sedimentary samples}

A core was collected and analyzed from beneath a high level waste tank (SX-108) that had leaked approximately $58 \mathrm{~m}^{3}$ of highly alkaline $\mathrm{NaNO}_{3}$ brine containing $1.51 \times 10^{15}$ Bq of ${ }^{137} \mathrm{Cs}$ (Jones et al., 2000) in the late 1960s. The subsurface sediments contain micas (biotite, muscovite), vermiculite, and smectite as defined in Zachara et al. (2002). The electrolyte concentration $\left(\mathrm{NaNO}_{3}\right)$ in the waste supernatant at the time of leakage is not known with certainty but has been estimated as $19 \mathrm{~mol} / \mathrm{l}$ (Lichtner, 2001). The waste solutions were hot $\left(\approx 100{ }^{\circ} \mathrm{C}\right)$ as a result of radioactive decay. Core samples from beneath the tank were collected in the summer of 2000 and analyzed for the concentrations of water soluble and total contaminants (Serne et al., 2001). The in-ground temperatures were still elevated at sampling time with the highest temperature of $73{ }^{\circ} \mathrm{C}$ at $30 \mathrm{~m}$ below ground surface (bgs).

Table 1

Thermodynamic data for aqueous $\mathrm{Cs}^{+}, \mathrm{Na}^{+}, \mathrm{K}^{+}$, and $\mathrm{NO}_{3}^{-}$system $\left(25^{\circ} \mathrm{C}\right)$

\begin{tabular}{llll}
\hline Binary Pitzer parameters & $\beta^{(0)}$ & $\beta^{(1)}$ & $C^{\phi}$ \\
$\mathrm{NaNO}_{3}{ }^{\mathrm{a}}$ & 0.00655 & 0.2561 & 0 \\
$\mathrm{KNO}_{3}$ & -0.0816 & 0.0494 & 0.00660 \\
$\mathrm{CsNO}_{3}$ & -0.0758 & -0.0669 & 0 \\
Mixing parameters & & \\
$\theta_{\mathrm{NaK}}=-0.012 ; \theta_{\mathrm{NaCs}}=-0.0153 ; \theta_{\mathrm{KCs}}=-0.0049 ;$ & & \\
Free energy of formation $\left(\Delta \mathrm{G}^{\mathrm{o}} / \mathrm{RT}\right)$ & & \\
$\mathrm{Na}^{+}=-105.651 ; \mathrm{K}^{+}=-113.957 ; \mathrm{Cs}^{+}=-119.966 ;$ & & \\
$\mathrm{NaNO}_{3}=-145.500$ & & \\
\hline
\end{tabular}

\footnotetext{
${ }^{a}$ Parameters considered ion-pair of $\mathrm{NaNO}_{3}$.
} 
The measured pore water composition (Serne et al., 2001) were used to calculate speciation and activities of water and aqueous species using GMIN computer code and its database (Felmy, 1995) with aqueous activity coefficients calculated by the Pitzer model. This calculation included all significant porewater electrolyte species (e.g., $\mathrm{K}^{+}, \mathrm{Na}^{+}, \mathrm{Ca}^{2+}$, $\mathrm{Mg}^{2+}, \mathrm{SO}_{4}^{2-}, \mathrm{Cl}^{-}$, and $\mathrm{NO}_{3}^{-}$) and $\mathrm{Cs}^{+}$. The activities of the calculated water and aqueous species were then used to predict the Cs sorption in the contaminated sediment based on the $\mathrm{Cs}$ ion exchange model and parameters characterized from the binary experiments performed using pristine "Above B Composite".

\section{Results and discussion}

\subsection{Ion exchange of $\mathrm{Cs}^{+}$for $\mathrm{K}^{+}$and $\mathrm{Cs}^{+}$for $\mathrm{Na}^{+}$}

The selectivity coefficients $\left(K_{\mathrm{v}}\right)$ for $\mathrm{Cs}^{+}$exchange on $\mathrm{K}^{+}$- and $\mathrm{Na}^{+}$-saturated sediments varied with $\mathrm{Cs}^{+}$-adsorption density and electrolyte concentration (Fig. 2). The selectivity coefficients increased with an increase in electrolyte concentration. This effect was observed even at lower electrolyte concentrations (from 0.01 to $0.1 \mathrm{~mol} / \mathrm{l}$ ). Similar experimental results were observed in Brouwer et al. (1983) where the $\mathrm{Cs}^{+}$selectivity coefficients on $\mathrm{Na}^{+}$and $\mathrm{K}^{+}$illite increased with increasing electrolyte concentration from 0.002 to $0.02 \mathrm{~mol} / \mathrm{l}$. The overall selectivity coefficients $\left(K_{\mathrm{v}}\right)$ (Fig. 2) at each electrolyte concentration were consistent with a two-site, exchange model (Zachara et al., 2002), with the overall selectivity coefficient expressed by:

$$
K_{\mathrm{v}}\left(E_{\mathrm{Cs}}\right)=\left(b+\sqrt{b^{2}+4 K_{\mathrm{v}}^{\mathrm{I}} K_{\mathrm{v}}^{\mathrm{II}} E_{\mathrm{Cs}}\left(1-E_{\mathrm{Cs}}\right)}\right) /\left(2-2 E_{\mathrm{Cs}}\right)
$$

where $b=\left(E^{\mathrm{I}}-E_{\mathrm{Cs}}\right) K_{\mathrm{v}}^{\mathrm{I}}+\left(1-E^{\mathrm{I}}-E_{\mathrm{Cs}}\right) K_{\mathrm{v}}^{\mathrm{II}} ; K_{\mathrm{v}}^{\mathrm{I}}$ and $K_{\mathrm{v}}^{\mathrm{II}}$ are the selectivity coefficients for sites I and II, respectively; and $E^{\mathrm{I}}$ is the fraction of the sediment CEC contributed by site I.

The two-site model well described the experimental results (solid line in Fig. 2). The modeling was performed by individually adjusting $K_{\mathrm{v}}^{\mathrm{I}}$ and $K_{\mathrm{v}}^{\mathrm{II}}$ in Eq. (21) for each exchange isotherm, while maintaining a single best fit value of $E^{\mathrm{I}}\left(4.5 \times 10^{-4}\right)$ for all isotherms. The values for $K_{\mathrm{v}}^{\mathrm{I}}$ and $K_{\mathrm{v}}^{\mathrm{II}}$ are summarized in Table 2 and plotted in Fig. 3.

The values of the fitted selectivity coefficients for the individual sites $\left(K_{\mathrm{v}}^{\mathrm{I}}\right.$ and $\left.K_{\mathrm{v}}^{\mathrm{II}}\right)$ increased with increasing $\mathrm{NaNO}_{3}$ and $\mathrm{KNO}_{3}$ concentration (Fig. 3). The extent of change in the selectivity coefficients was greater in $\mathrm{Na}^{+}$- than $\mathrm{K}^{+}$-electrolyte, as also observed in Brouwer et al. (1983). These electrolyte differences were consistent with the hydration energy of the exchanging ions: $\mathrm{Na}^{+}>\mathrm{K}^{+}>\mathrm{Cs}^{+}$.

The fitted $K_{\mathrm{v}}$ values (Table 2, Fig. 3) can be used to estimate the difference of moles of water per equivalent exchange capacity associated with exchanging cations (e.g., $n_{\mathrm{w}}^{\mathrm{Na}}-n_{\mathrm{w}}^{\mathrm{Cs}}$ ) at each exchange site as follows. Applying (Eq. (18)) to the individual exchange site and considering Eqs. (19) and (20) for monovalent exchange, we obtained:

$$
\ln K_{\mathrm{v}}^{\mathrm{i}}\left(\ln a_{\mathrm{w}}\right)=\ln K_{\mathrm{ex}}^{\mathrm{i}}+\int_{0}^{\ln a_{\mathrm{w}}}\left[n_{\mathrm{w}}^{\mathrm{i}, \mathrm{Cs}}\left(\ln a_{\mathrm{w}}^{\prime}\right)-n_{\mathrm{w}}^{\mathrm{i}, \mathrm{A}}\left(\ln a_{\mathrm{w}}^{\prime}\right)\right] \mathrm{d} \ln a_{\mathrm{w}}^{\prime}
$$



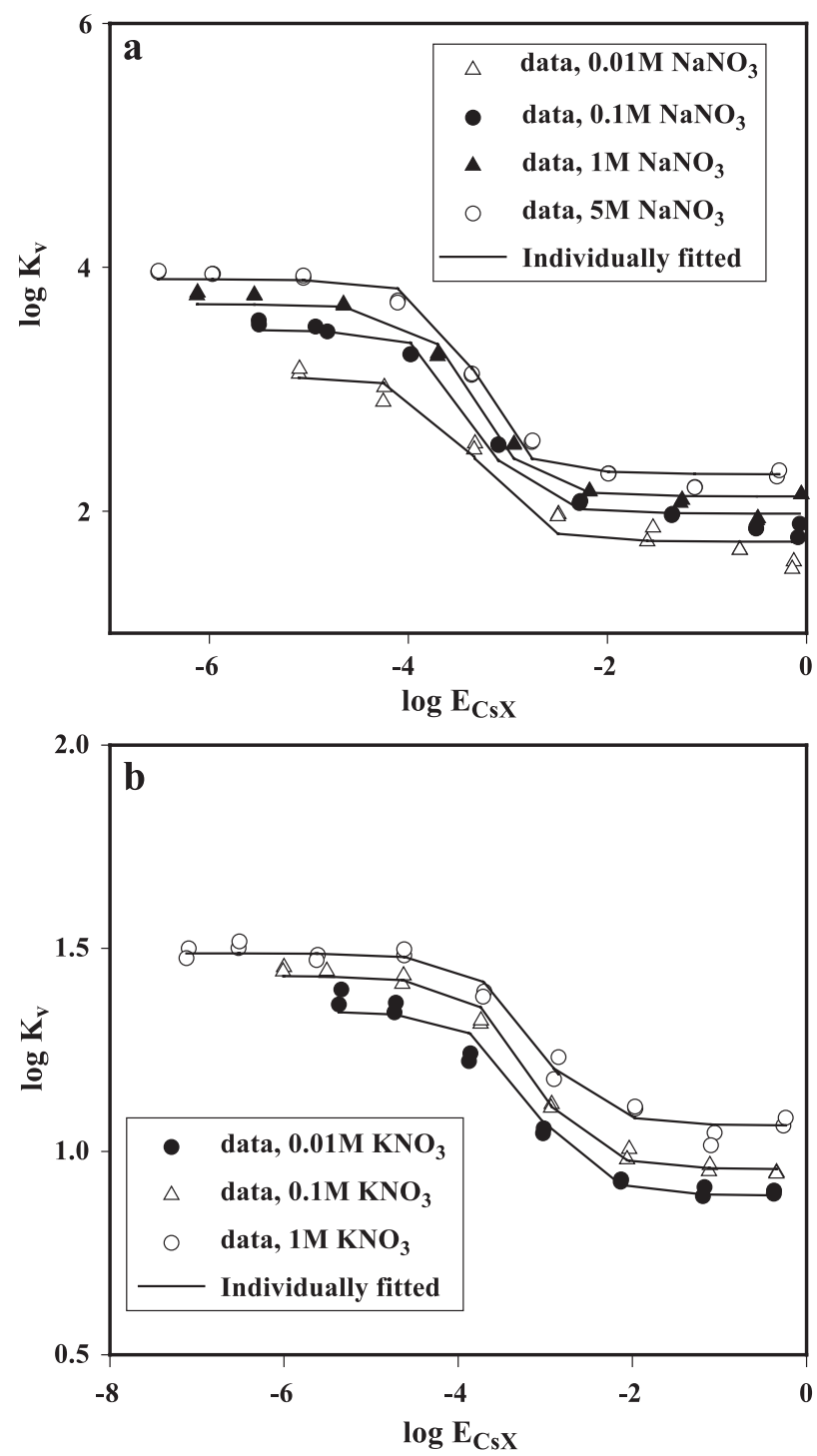

Fig. 2. $\mathrm{Cs}^{+}$exchange selectivity coefficients on Hanford sediment in $\mathrm{Na}^{+}$(a) and $\mathrm{K}^{+}$(b) electrolyte as a function of ionic strength and exchange composition. Each isotherm was fitted by a two-site model (text).

where i denotes site I or II. After averaging Eq. (22) along a constant electrolyte concentration (note that $K_{\mathrm{v}}^{\mathrm{i}}$ values in Table 2 were estimated from experiments performed at constant electrolyte concentration), the difference of $\ln K_{\mathrm{v}}^{\mathrm{i}}$ at two ionic strengths can be expressed as:

$$
\ln K_{\mathrm{v}}^{\mathrm{i}}\left(\mathrm{I}_{2}\right)-\ln K_{\mathrm{v}}^{\mathrm{i}}\left(\mathrm{I}_{1}\right)=\left(\bar{n}_{\mathrm{w}}^{\mathrm{i}, \mathrm{Cs}}-\bar{n}_{\mathrm{w}}^{\mathrm{i}, \mathrm{A}}\right)\left(\ln \bar{a}_{\mathrm{w}}\left(\mathrm{I}_{2}\right)-\ln \bar{a}_{\mathrm{w}}\left(\mathrm{I}_{1}\right)\right)
$$


Table 2

Fitted parameters for individual isotherms

\begin{tabular}{|c|c|c|c|c|c|c|}
\hline & \multicolumn{2}{|l|}{$\mathrm{Cs}-\mathrm{K}$} & \multicolumn{2}{|l|}{$\mathrm{Cs}-\mathrm{Na}$} & \multicolumn{2}{|l|}{$\mathrm{K}-\mathrm{Na}^{\mathrm{a}}$} \\
\hline & $\log K_{\mathrm{v}}^{\mathrm{I}}$ & $\log K_{\mathrm{v}}^{\mathrm{II}}$ & $\log K_{\mathrm{v}}^{\mathrm{I}}$ & $\log K_{\mathrm{v}}^{\mathrm{II}}$ & $\log K_{\mathrm{v}}^{\mathrm{I}}$ & $\log K_{\mathrm{v}}^{\mathrm{II}}$ \\
\hline $0.01 \mathrm{M}$ & $4.503 \pm 0.024$ & $0.891 \pm 0.012$ & $6.429 \pm 0.064$ & $1.749 \pm 0.043$ & 1.926 & 0.858 \\
\hline $0.1 \mathrm{M}$ & $4.592 \pm 0.015$ & $0.956 \pm 0.008$ & $6.820 \pm 0.052$ & $1.979 \pm 0.039$ & 2.228 & 1.023 \\
\hline $1 \mathrm{M}$ & $4.629 \pm 0.015$ & $1.064 \pm 0.009$ & $7.033 \pm 0.047$ & $2.121 \pm 0.041$ & 2.404 & 1.057 \\
\hline $5 \mathrm{M}$ & & & $7.239 \pm 0.029$ & $2.302 \pm 0.028$ & & \\
\hline
\end{tabular}

${ }^{\text {a }}$ Calculated from fitted $\mathrm{K}_{\mathrm{v}}$ of $\mathrm{Cs}-\mathrm{Na}$ and $\mathrm{Cs}-\mathrm{K}$. The numbers in () are standard deviations.

where $\mathrm{I}_{1}$ and $\mathrm{I}_{2}$ are the ionic strengths 1 and 2, respectively, and $\bar{n}_{\mathrm{w}}^{\mathrm{i}, \mathrm{A}}$ and $\bar{n}_{\mathrm{w}}^{\mathrm{i}, \mathrm{CS}}$ are the number of moles of water per equivalent exchange capacity at site $\mathrm{i}$ for homoionic $\mathrm{AX}$ and CsX, respectively, averaged from $\ln \bar{a}_{\mathrm{w}}\left(I_{1}\right)$ to $\ln \bar{a}_{\mathrm{w}}\left(\mathrm{I}_{2}\right)$. The mean water activity $\left(\bar{a}_{\mathrm{w}}\right)$ was averaged from $E_{\mathrm{Cs}}=0$ to $E_{\mathrm{Cs}}=1$ along a constant electrolyte concentration. Eq. (23) was then used to estimate $\Delta n_{\mathrm{w}}^{\mathrm{i}}\left(\right.$ e.g., $\left.\bar{n}_{\mathrm{w}}^{\mathrm{i}, \mathrm{Na}}-\bar{n}_{\mathrm{w}}^{\mathrm{i}, \mathrm{CS}}\right)\left(\mathrm{i}=\mathrm{I}\right.$, II) using the fitted $K_{\mathrm{v}}^{\mathrm{i}}$ values and calculated water activity from the Pitzer model at different electrolyte concentrations (Table 2). The estimated $\bar{n}_{\mathrm{w}}^{\mathrm{Na}}-\bar{n}_{\mathrm{w}}^{\mathrm{Cs}}$ was 45 and 28 and $\bar{n}_{\mathrm{w}}^{\mathrm{K}}-\bar{n}_{\mathrm{w}}^{\mathrm{Cs}}$ was 11 and 14 at sites I and II, respectively, over the ionic strength range from 0.01 to 1 . The $\Delta n_{\mathrm{w}}$ (e.g., $\bar{n}_{\mathrm{w}}^{\mathrm{Na}}$ $\left.-\bar{n}_{\mathrm{w}}^{\mathrm{Cs}}\right)$ decreased with increasing water activity $\left(\ln \bar{a}_{\mathrm{w}}\right)$ in accordance with the smaller increase in $K_{\mathrm{v}}$ with increasing electrolyte concentration (Fig. 3). However, the trend

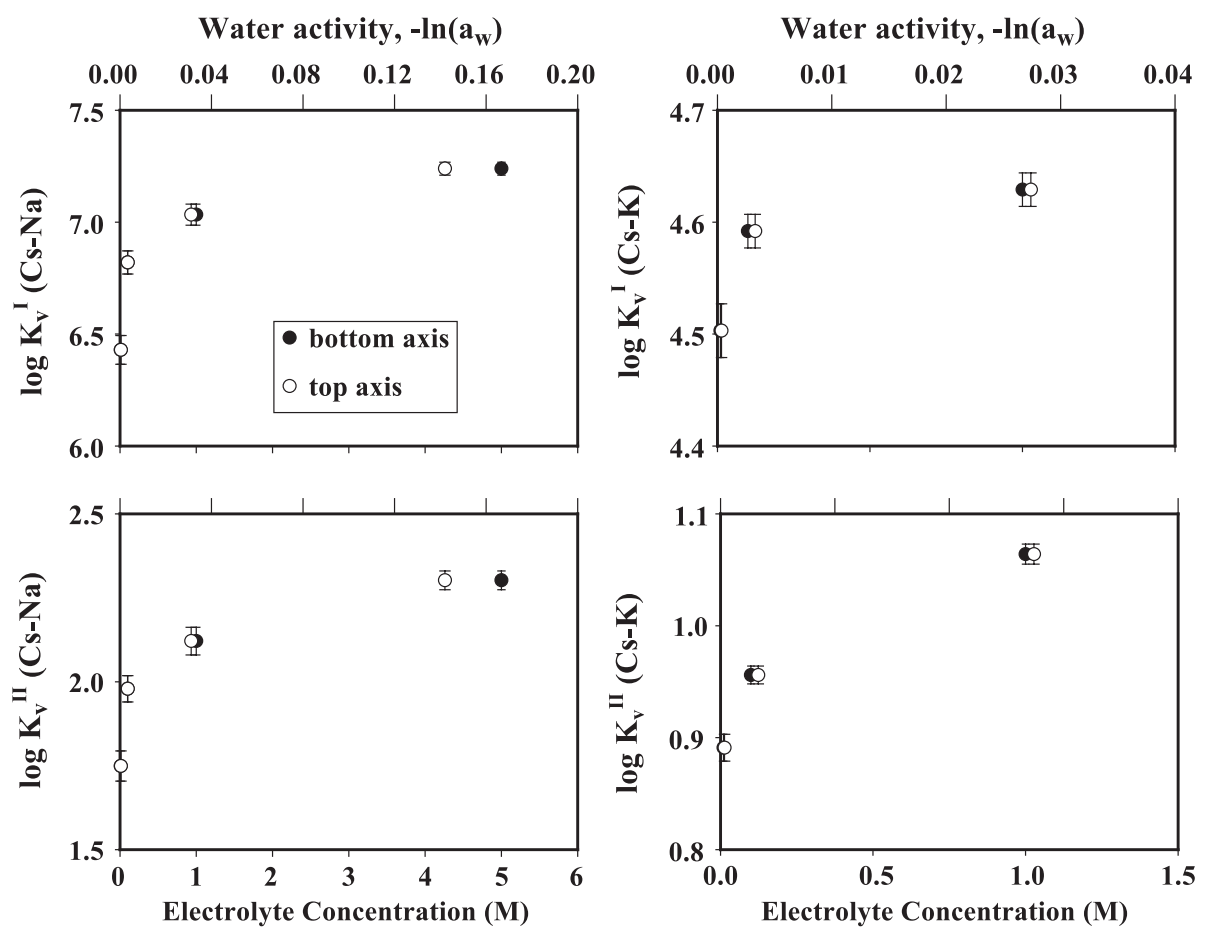

Fig. 3. Fitted selectivity coefficients as functions of water activity (or ionic strength). 
$\bar{n}_{\mathrm{w}}^{\mathrm{Na}}>\bar{n}_{\mathrm{w}}^{\mathrm{K}}>\bar{n}_{\mathrm{w}}^{\mathrm{Cs}}$ that was consistent with ionic hydration energy was maintained throughout the analysis. Our derived/fitted water contents were consistent with (i) theoretical calculations that showed that clay water content per equivalent exchange capacity $\left(n_{\mathrm{w}}\right)$ decreased during the replacement of $\mathrm{Na}^{+}$by $\mathrm{Cs}^{+}$(Eberl, 1980), and (ii) experimental measurements of the water contents of zeolite, which showed $\bar{n}_{\mathrm{w}}^{\mathrm{Na}}>\bar{n}_{\mathrm{w}}^{\mathrm{K}}$ (Barrer and Klinowski, 1974).

The individual site selectivity coefficients (Table 2) had a difference of up to 0.8 (4.5 $\mathrm{kJ} / \mathrm{eq}$ ) common logarithmic units (or energy) in the exchange of $\mathrm{Cs}^{+}$for $\mathrm{Na}^{+}$and $0.2(1.1$ $\mathrm{kJ} / \mathrm{eq}$ ) for $\mathrm{Cs}^{+}-\mathrm{K}^{+}$exchange, within the measured range of electrolyte concentration. These differences in $K_{\mathrm{v}}$ values were significant considering that experimental error in $K_{\mathrm{v}}$ determination as less than $0.064(0.36 \mathrm{~kJ} / \mathrm{eq})$ common logarithmic units (or energy) in the exchange of $\mathrm{Cs}^{+}$for $\mathrm{Na}^{+}$and $0.024(0.14 \mathrm{~kJ} / \mathrm{eq})$ in $\mathrm{Cs}^{+}$for $\mathrm{K}^{+}$(Table 2).

Eq. (22) indicated that the selectivity coefficient at an individual site at any water activity can generally be described as:

$$
\log K_{\mathrm{v}}^{\mathrm{i}}\left(\ln a_{\mathrm{w}}\right)=\log K_{\mathrm{ex}}^{\mathrm{i}}+F^{\mathrm{i}}\left(\ln a_{\mathrm{w}}\right) \quad \mathrm{i}=\mathrm{I} \text { and II }
$$

where $F^{\mathrm{i}}\left(\ln a_{\mathrm{w}}\right)=\log e \int_{0}^{\ln a_{\mathrm{w}}}\left[n_{\mathrm{w}}^{\mathrm{i}, \mathrm{Cs}}\left(\ln a_{\mathrm{w}}^{\prime}\right)-n_{\mathrm{w}}^{\mathrm{i}, \mathrm{A}}\left(\ln a_{\mathrm{w}}^{\prime}\right)\right] \mathrm{d} \ln a_{\mathrm{w}}^{\prime}$. Because the $\Delta n_{\mathrm{w}}^{\mathrm{i}}\left(\mathrm{e} . \mathrm{g} ., \bar{n}_{\mathrm{w}}^{\mathrm{i}, \mathrm{Na}}\right.$ $\left.-\bar{n}_{\mathrm{w}}^{\mathrm{i}, \mathrm{Cs}}\right)$ in Eq. (24a) and (24b) changes with ionic strength, $n_{\mathrm{w}}^{\mathrm{i}, \mathrm{Cs}}\left(\ln a_{\mathrm{w}}\right)-n_{\mathrm{w}}^{\mathrm{i}, \mathrm{A}}\left(\ln a_{\mathrm{w}}\right)$ is not a constant, and thus $F^{\mathrm{i}}\left(\ln a_{\mathrm{w}}\right)$ is not a linear function of $\ln a_{\mathrm{w}}$. The function that best fitted the observed relationship (Fig. 3) with the minimum number of parameters was:

$$
F^{\mathrm{i}}\left(\ln a_{\mathrm{w}}\right)=k^{\mathrm{i}} \sqrt{-\ln a_{\mathrm{w}}} /\left(1+\sqrt{-\ln a_{\mathrm{w}}}\right) \quad \mathrm{i}=1 \text { and II }
$$

where $k^{\mathrm{i}}$ is a fit parameter for site $\mathrm{i}$.

Because Cs sorption is typically described by a distribution coefficient $\left(K_{\mathrm{d}}\right)$ of Cs between exchanger and aqueous phases in practice, we derived a relationship between $K_{\mathrm{d}}$ and $K_{\mathrm{v}}^{\mathrm{i}}(\mathrm{i}=\mathrm{I}, \mathrm{II})$ for binary, monovalent exchange system:

$$
K_{\mathrm{d}}(\mathrm{Cs})=\sum_{i=1}^{\mathrm{L}} N_{\mathrm{Cs}}^{i} E^{i} \mathrm{CEC} / C_{\mathrm{Cs}^{+}}=\sum_{i=1}^{\mathrm{L}}\left(\frac{K_{\mathrm{v}}^{i} \gamma_{\mathrm{Cs}^{+}} E^{i}}{K_{\mathrm{v}}^{i} a_{\mathrm{Cs}^{+}}+a_{\mathrm{A}^{+}}}\right) C E C
$$

where $L$ is the number of exchange sites (two for this case); $\gamma_{\mathrm{Cs}}+$ is the activity coefficient of $\mathrm{Cs}^{+}$in aqueous phase; $E^{\mathrm{i}}$ is the equivalent fraction of site $i$, and $N_{\mathrm{Cs}}^{\mathrm{i}}$ is the equivalent fraction of $\mathrm{Cs}$ in exchanger site $i$. Other symbols are defined before.

Eq. (25) with $K_{\mathrm{v}}^{\mathrm{i}}$ described by Eq. (24a) and (24b) and activity coefficients of Cs and exchanging cations $\left(\mathrm{Na}^{+}, \mathrm{K}^{+}\right)$calculated from GMIN was used to simultaneously fit experimental $K_{\mathrm{d}}$ results of $\mathrm{Cs}$ at variable ionic strengths by adjusting 3 parameters: $K_{\mathrm{ex}}^{\mathrm{I}}$, $K_{\mathrm{ex}}^{\mathrm{II}}$, and $k\left[K_{\mathrm{ex}}^{\mathrm{I}}\right.$ and $K_{\mathrm{ex}}^{\mathrm{II}}$ are exchange constants at site I and II, respectively; $k$ is assumed to be the same on both sites because the $K_{\mathrm{v}}$ changes with water activity for sites I and II were the similar (Fig. 3)]. An equivalent fraction of $4.5 \times 10^{-4}$ was used for site $\mathrm{I}\left(E^{\mathrm{I}}\right)$ in all the data analysis. Model (25) well described the ionic strength dependence of Cs sorption (Fig. 4) with the fitted parameters listed in Table 3. The overall $K_{\mathrm{v}}$ values (not shown) calculated using Eq. (21) with $K_{\mathrm{v}}^{\mathrm{i}}$ calculated from Eq. (24a) and (24b) using the fitted $K_{\mathrm{ex}}^{\mathrm{I}}$, and $K_{\mathrm{ex}}^{\mathrm{II}}$, and $k$ (Table 3 ) were almost identical to the fitted $K_{v}$ values in Fig. 2. 

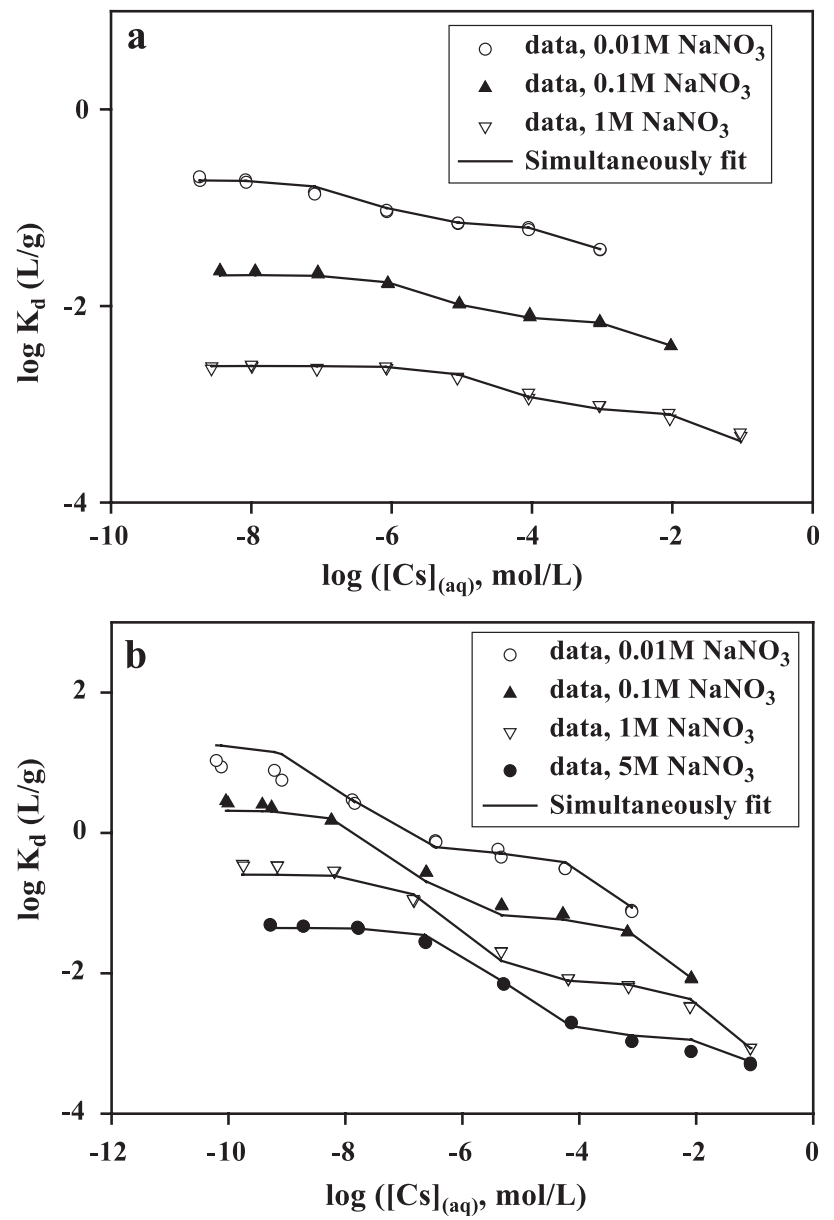

Fig. 4. Experimental and modeling results of $\mathrm{Cs}^{+}$distribution coefficient $\left(K_{\mathrm{d}}\right)$ as a function of aqueous $\mathrm{Cs}^{+}$ concentration and ionic strength. The experimental results were fitted simultaneously using a two-site model corrected by a water activity effect. (a) $\mathrm{Cs}^{+}$in $\mathrm{KNO}_{3}$ electrolyte and (b) $\mathrm{Cs}^{+}$in $\mathrm{NaNO}_{3}$ electrolyte.

\subsection{Ion exchange of $\mathrm{K}-\mathrm{Na}$}

Eq. (24a) and (24b) indicates that nonideality of binary cation exchange in the system of $\mathrm{Na}^{+}, \mathrm{K}^{+}$, and $\mathrm{Cs}^{+}$is independent of fractional site occupation $\left(E_{\mathrm{CS}}^{\mathrm{i}}\right)$ on each site at a

Table 3

Fitted parameters

\begin{tabular}{llll}
\hline & $\log K_{\mathrm{ex}}^{\mathrm{I}}$ & $\log K_{\mathrm{ex}}^{\mathrm{II}}$ & $k$ \\
\hline $\mathrm{Cs}-\mathrm{K}$ & $4.502 \pm 0.014$ & $0.889 \pm 0.010$ & $1.139 \pm 0.449$ \\
$\mathrm{Cs}-\mathrm{Na}$ & $6.637 \pm 0.036$ & $1.761 \pm 0.034$ & $2.259 \pm 0.177$ \\
$\mathrm{~K}-\mathrm{Na}^{\mathrm{a}}$ & 2.135 & 0.872 & 1.120 \\
\hline
\end{tabular}

\footnotetext{
${ }^{\text {a }}$ Calculated from $\mathrm{Cs}-\mathrm{K}$ and $\mathrm{Cs}-\mathrm{Na}$.
} 
constant water activity. Accordingly, the exchange constants $\left(K_{\mathrm{ex}}^{\mathrm{i}}\right)$ for $\mathrm{K}^{+}-\mathrm{Na}^{+}$on each site must be the same as the $K_{\mathrm{ex}}^{\mathrm{i}}$ difference between $\mathrm{Cs}^{+}-\mathrm{K}^{+}$and $\mathrm{Cs}^{+}-\mathrm{Na}^{+}$exchanges. The activity correction term for $\mathrm{K}^{+}-\mathrm{Na}^{+}$with respect to water activity was also related to the $\mathrm{Cs}^{+}-\mathrm{K}^{+}$and $\mathrm{Cs}^{+}-\mathrm{Na}^{+}$system in the following manner:

$$
\log \left(f_{\mathrm{Na}}^{\mathrm{i}, \mathrm{p}} / f_{\mathrm{K}}^{\mathrm{i}, \mathrm{p}}\right)=\log \left(f_{\mathrm{Na}}^{\mathrm{i}, \mathrm{p}} / f_{\mathrm{Cs}}^{\mathrm{i}, \mathrm{p}}\right)-\log \left(f_{\mathrm{K}}^{\mathrm{i}, \mathrm{p}} / f_{\mathrm{Cs}}^{\mathrm{i}, \mathrm{p}}\right) \quad \mathrm{i}=\mathrm{I} \text { and II }
$$

where $\log \left(f_{\mathrm{Na}}^{\mathrm{i}, \mathrm{p}} / f_{\mathrm{Cs}}^{\mathrm{i}, \mathrm{p}}\right)$ and $\log \left(f_{\mathrm{K}}^{\mathrm{i}, \mathrm{p}} / f_{\mathrm{Cs}}^{\mathrm{i}, \mathrm{p}}\right)$ have been determined to be $F^{\mathrm{i}}\left(\ln a_{\mathrm{w}}\right)$ in Eq. $(24 \mathrm{a})$ and (24b) for $\mathrm{Na}^{+}-\mathrm{Cs}^{+}$and $\mathrm{K}^{+}-\mathrm{Cs}^{+}$exchanges, respectively. We used Eq. (21) with its Cs replaced by $\mathrm{K}$, and the calculated exchange constants and the activity correction term using Eq. (26) from $\mathrm{Cs}^{+}-\mathrm{K}^{+}$and $\mathrm{Cs}^{+}-\mathrm{Na}^{+}$exchanges (Table 3) to predict $\mathrm{Na}^{+}-\mathrm{K}^{+}$ exchange, which was compared with experimental results (Fig. 5).

In both $\mathrm{NaNO}_{3}$ and $\mathrm{KNO}_{3}$ electrolytes, we had difficulty achieving high enough $\mathrm{Na}^{+}$ adsorption densities, which examine the exchange behavior of the high affinity site. In the $\mathrm{KNO}_{3}$ electrolyte, only a small amount of $\mathrm{Na}^{+}$was adsorbed by the exchanger because of the high selectivity of $\mathrm{K}^{+}$for both exchange sites. In $\mathrm{NaNO}_{3}$ electrolyte, the smallest adsorption density of $\mathrm{K}^{+}$achieved was about $0.4 \%$ of total CEC or $3.33 \times 10^{-7} \mathrm{~mol} / \mathrm{g}$. However, this amount was still larger than the high affinity site capacity of $0.045 \%$ of CEC. Consequently, the high affinity site was occupied by $\mathrm{K}^{+}$in all the $\mathrm{Na}^{+}-\mathrm{K}^{+}$exchange experiments. Lower $\mathrm{K}^{+}$concentrations could not be achieved because of $\mathrm{K}^{+}$contamination in the $\mathrm{NaNO}_{3}$ solution and continued trace $\mathrm{K}^{+}$dissolution from orthoclase and biotite in the soils. Therefore, our simulations of $\mathrm{K}^{+}-\mathrm{Na}^{+}$exchange were performed on only the low affinity site.

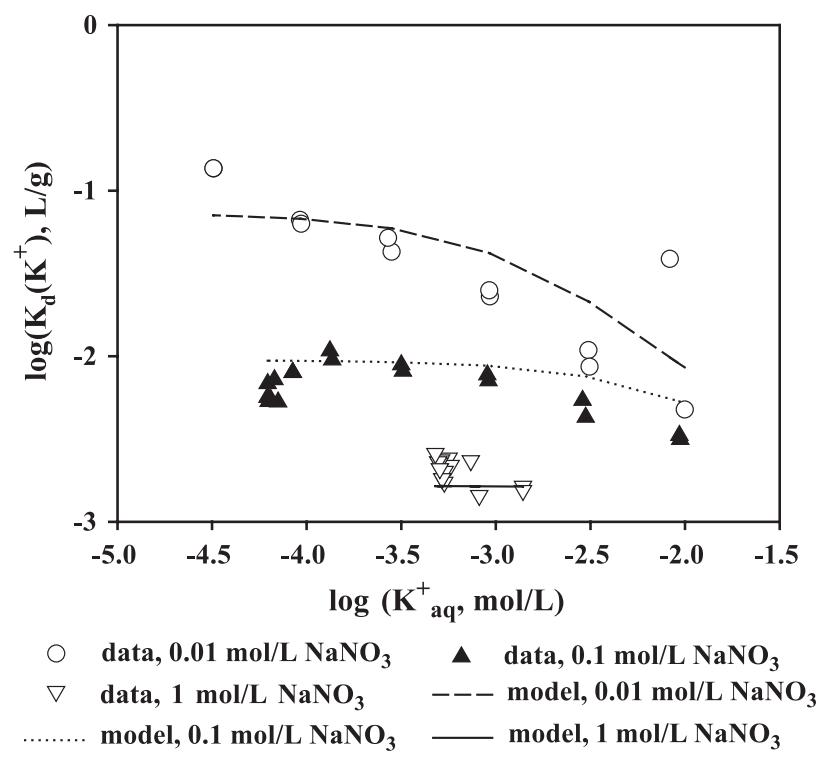

Fig. 5. Experimental and model predictions of $\mathrm{Na}^{+}-\mathrm{K}^{+}$exchange showing potassium distribution as a function of aqueous $\mathrm{K}^{+}$and $\mathrm{NaNO}_{3}$ electrolyte concentrations. 
The ion exchange model using the parameters calculated from $\mathrm{Cs}^{+}-\mathrm{Na}^{+}$and $\mathrm{Cs}^{+}-\mathrm{K}^{+}$ data (Table 2) generally predicted $\mathrm{Na}^{+}-\mathrm{K}^{+}$exchange well (Fig. 5). The predictions were better for the $\mathrm{NaNO}_{3}$ than the $\mathrm{KNO}_{3}$ electrolyte (not shown) because of the better measurement statistics of the former system.

\subsection{Prediction of $C s$ distribution in field}

Because the binary exchange behavior of $\mathrm{Cs}^{+}-\mathrm{Na}^{+}$and $\mathrm{Cs}^{+}-\mathrm{K}^{+}$on the two individual sites were independent of exchange composition, we felt justified in using the binary exchange constants to forecast ternary exchange $\left(\mathrm{Cs}^{+}-\mathrm{Na}^{+}-\mathrm{K}^{+}\right)$in the field. Three exchange reactions are needed to describe the ternary system (Fletcher and Townsend, 1981):

$$
\begin{aligned}
& 2 \mathrm{NaX}+K^{+}+\mathrm{Cs}^{+}=2 \mathrm{Na}^{+}+\mathrm{KX}+\mathrm{CsX} \\
& \mathrm{Na}^{+}+2 \mathrm{KX}+\mathrm{Cs}^{+}=\mathrm{NaX}+2 K^{+}+\mathrm{CsX} \\
& \mathrm{Na}^{+}+K^{+}+2 \mathrm{CsX}=\mathrm{NaX}+\mathrm{KX}+2 \mathrm{Cs}^{+}
\end{aligned}
$$

Because only two of these reactions are independent, we only considered reactions (27) and (28) in the following analysis. The thermodynamic equilibrium constants, $K_{\mathrm{T} 1}$ and $K_{\mathrm{T} 2}$, corresponding to these two reactions may be calculated from the binary reactions and are defined as follows:

$$
\begin{aligned}
& K_{\mathrm{T} 1}^{\mathrm{i}}=\frac{a_{\mathrm{Na}^{+}}^{2} a_{\mathrm{KX}}^{i} a_{\mathrm{CsX}}^{i}}{\left(a_{\mathrm{NaX}}^{i}\right)^{2} a_{\mathrm{K}^{+}} a_{\mathrm{Cs}^{+}}}=K_{\mathrm{ex}}^{\mathrm{i}}(\mathrm{Cs}-\mathrm{Na}) K_{\mathrm{eX}}^{\mathrm{i}}(\mathrm{K}-\mathrm{Na}) \quad \mathrm{i}=\mathrm{I}, \mathrm{II} \\
& K_{\mathrm{T} 2}^{\mathrm{i}}=\frac{a_{\mathrm{NaX}}^{i} a_{K^{+}}^{2} a_{\mathrm{CsX}}^{i}}{a_{\mathrm{Na}^{+}}\left(a_{\mathrm{KX}}^{i}\right)^{2} a_{\mathrm{Cs}^{+}}}=K_{\mathrm{ex}}^{\mathrm{i}}(\mathrm{Cs}-\mathrm{K}) / K_{\mathrm{ex}}^{\mathrm{i}}(\mathrm{K}-\mathrm{Na}) \mathrm{i}=\mathrm{I}, \mathrm{II}
\end{aligned}
$$

where $K_{\mathrm{ex}}^{\mathrm{i}}(\mathrm{B}-\mathrm{A})$ is the equilibrium constant of $\mathrm{B}\left(\mathrm{e} . \mathrm{g} ., \mathrm{Cs}^{+}\right)$to replace $\mathrm{A}$ (e.g., $\mathrm{Na}^{+}$) in the binary exchange reaction at site $\mathrm{i}$ (Table 3). Because the individual site activity coefficients were independent of exchange composition but dependent on water activity, the ternary selectivity (or Kielland) coefficient was estimated as follows:

$$
\begin{aligned}
& \log K_{\mathrm{Ki}}^{\mathrm{i}}=\log \left(\frac{a_{\mathrm{Na}+}^{2} N_{\mathrm{KX}}^{i} N_{\mathrm{CsX}}^{i}}{\left(N_{\mathrm{NaX}}^{i}\right)^{2} a_{K^{+}} a_{\mathrm{Cs}^{+}}}\right)=\log K_{\mathrm{T} 1}^{\mathrm{i}}+\log \left(\frac{f_{\mathrm{Na}}^{\mathrm{i}, \mathrm{p}}\left(\ln a_{\mathrm{W}}\right) f_{\mathrm{Na}}^{\mathrm{i}, \mathrm{p}}\left(\ln a_{\mathrm{W}}\right)}{f_{\mathrm{K}}^{\mathrm{i}, \mathrm{p}}\left(\ln a_{\mathrm{W}}\right) f_{\mathrm{Cs}}^{\mathrm{i}, \mathrm{p}}\left(\ln a_{\mathrm{W}}\right)}\right) \mathrm{i}=\mathrm{I}, \mathrm{II} \\
& \log K_{\mathrm{K} 2}^{\mathrm{i}}=\log \left(\frac{N_{\mathrm{NaX}}^{i} a_{K^{+}}^{2} N_{\mathrm{CsX}}^{i}}{a_{\mathrm{Na}^{+}}\left(N_{\mathrm{KX}}^{i}\right)^{2} a_{\mathrm{Cs}^{+}}}\right)=\log K_{\mathrm{T} 2}^{\mathrm{i}}+\log \left(\frac{f_{\mathrm{K}}^{\mathrm{i}, \mathrm{p}}\left(\ln a_{\mathrm{w}}\right) f_{\mathrm{K}}^{\mathrm{i}, \mathrm{p}}\left(\ln a_{\mathrm{W}}\right)}{f_{\mathrm{Na}}^{\mathrm{i}, \mathrm{p}}\left(\ln a_{\mathrm{w}}\right) f_{\mathrm{Cs}}^{\mathrm{i}, \mathrm{p}}\left(\ln a_{\mathrm{W}}\right)}\right) \mathrm{i}=\mathrm{I}, \mathrm{II}
\end{aligned}
$$


The second term on the right hand side is a function of $\ln a_{\mathrm{w}}$ and can be evaluated using water activity correction term $F^{\mathrm{i}}\left(\ln a_{\mathrm{w}}\right)\left(\right.$ Eq. (24b)) from binary $\mathrm{Na}^{+}-\mathrm{Cs}^{+}, \mathrm{K}^{+}-$ $\mathrm{Cs}^{+}$, and $\mathrm{Na}^{+}-\mathrm{K}^{+}$exchanges with $\mathrm{k}$ values listed in Table 3. Note that the relationships (Eqs. (32) and (33)) apply specifically to the individual sites (e.g., high and low affinity). The overall selectivity coefficient for the ternary system may be calculated from Eqs. (32) and (33). The Kielland coefficients are related to $K_{\mathrm{d}}(\mathrm{Cs})$ by a following equation:

$$
\begin{aligned}
K_{\mathrm{d}}(\mathrm{Cs}) & =\frac{\sum_{i=1}^{L} N_{\mathrm{Cs}}^{i} E^{i} \mathrm{CEC}}{C_{\mathrm{Cs}^{+}}} \\
& =\sum_{i=1}^{N}\left(C_{\mathrm{Cs}^{+}}+\frac{a_{\mathrm{K}^{+}} / \gamma_{\mathrm{Cs}^{+}}}{\sqrt[3]{K_{\mathrm{K} 1}^{i} K_{\mathrm{K} 2}^{i} K_{\mathrm{K} 2}^{i}}}+\frac{a_{\mathrm{Na}^{+}} / \gamma_{\mathrm{Cs}^{+}}}{\sqrt[3]{K_{\mathrm{K} 1}^{i} K_{\mathrm{K} 1}^{i} K_{\mathrm{K} 2}^{i}}}\right)^{-1} E^{i} \mathrm{CEC}
\end{aligned}
$$

The ternary exchange model (34) was applied to predict Cs distribution at a core location beneath a high level waste tank (SX-108). Selected analytes in porewater of the sediment in this core are shown in Fig. 6. Clearly defined are two peaks in $\mathrm{NaNO}_{3(\mathrm{aq})}$, one at depth of $25-31 \mathrm{~m}(12-16 \mathrm{~mol} / \mathrm{l})$ and another at $35-41 \mathrm{~m}$ with $(3-5 \mathrm{~mol} / \mathrm{l})$. The peak concentrations of $\mathrm{NaNO}_{3(\mathrm{aq})}$ exceed the known, room temperature $\left(25^{\circ} \mathrm{C}\right)$ solubility of $\mathrm{NaNO}_{3(\mathrm{~s})}(\approx 9 \mathrm{~mol} / \mathrm{l})$, apparently because in-ground temperatures are still elevated $\left(73{ }^{\circ} \mathrm{C}\right.$ at $30 \mathrm{~m}$ ). The low electrolyte concentrations in porewater from 17 to $22 \mathrm{~m}$ result from the infiltration of meteoric waters after the tank leak event. The peak concentrations in ${ }^{137} \mathrm{Cs}$ occur at a shallower depth (e.g., $25 \mathrm{~m}$ ) than that for $\mathrm{NaNO}_{3(\mathrm{aq})}$ as a result of retardation by ion exchange. The water soluble and total ${ }^{137} \mathrm{Cs}$ activities in the various samples were used to calculate in situ concentration distribution ratios $\left(K_{\mathrm{d}}, \mathrm{ml} / \mathrm{g}\right)$, Fig. 7a. The in situ $K_{\mathrm{d}} \mathrm{s}$ varied by over four orders of magnitude, with the lowest values noted where $\mathrm{NaNO}_{3(\mathrm{aq})}$ was highest $(25-31 \mathrm{~m})$ as expected from mass action considerations.

$K_{\mathrm{d}}$ predictions (Fig. 7a) were made using $K_{\mathrm{K}}$ values calculated from $K_{\mathrm{v}}$ values as a function of ionic strength (Eq. (24a) and (24b)) (Model 1-water activity corrected), and the ionic strength-averaged $K_{\mathrm{v}}$ values estimated from the binary system of exchange data of $\mathrm{Cs}^{+}-\mathrm{Na}^{+}$and $\mathrm{Cs}^{+}-\mathrm{K}^{+}$(Model 2-not corrected for water activity). The $K_{\mathrm{d}}$ calculation ignored the potential competitive effects of $\mathrm{Ca}^{2+}$ and $\mathrm{Mg}^{2+}$ because their concentrations were quite low and swamped by $\mathrm{Na}^{+}$and $\mathrm{K}^{+}$. The $K_{\mathrm{d}}$ calculation also assumed a single value of CEC $\left(8.25 \times 10^{-5} \mathrm{eq} / \mathrm{g}\right)$ over the entire depth interval. We have measured CEC of various samples from this sediment column and found that it did not vary appreciably ( $\pm 20 \%$ ). Water activity was computed to vary significantly with depth as a result of high electrolyte concentration associated with the leaked HLW (Fig. 7b). Generally, the predictions of both models were close to one another, except at locations of high ionic strength and low water activity (e.g., 24-32 m). At these same locations, the water activity-corrected model (Model 1) better described the field data, yielding $K_{\mathrm{d}}$ predictions that were an order of magnitude closer to the field observation. These results indicated that field distribution of $\mathrm{Cs}^{+}$may be close to the ion exchange equilibrium state. 

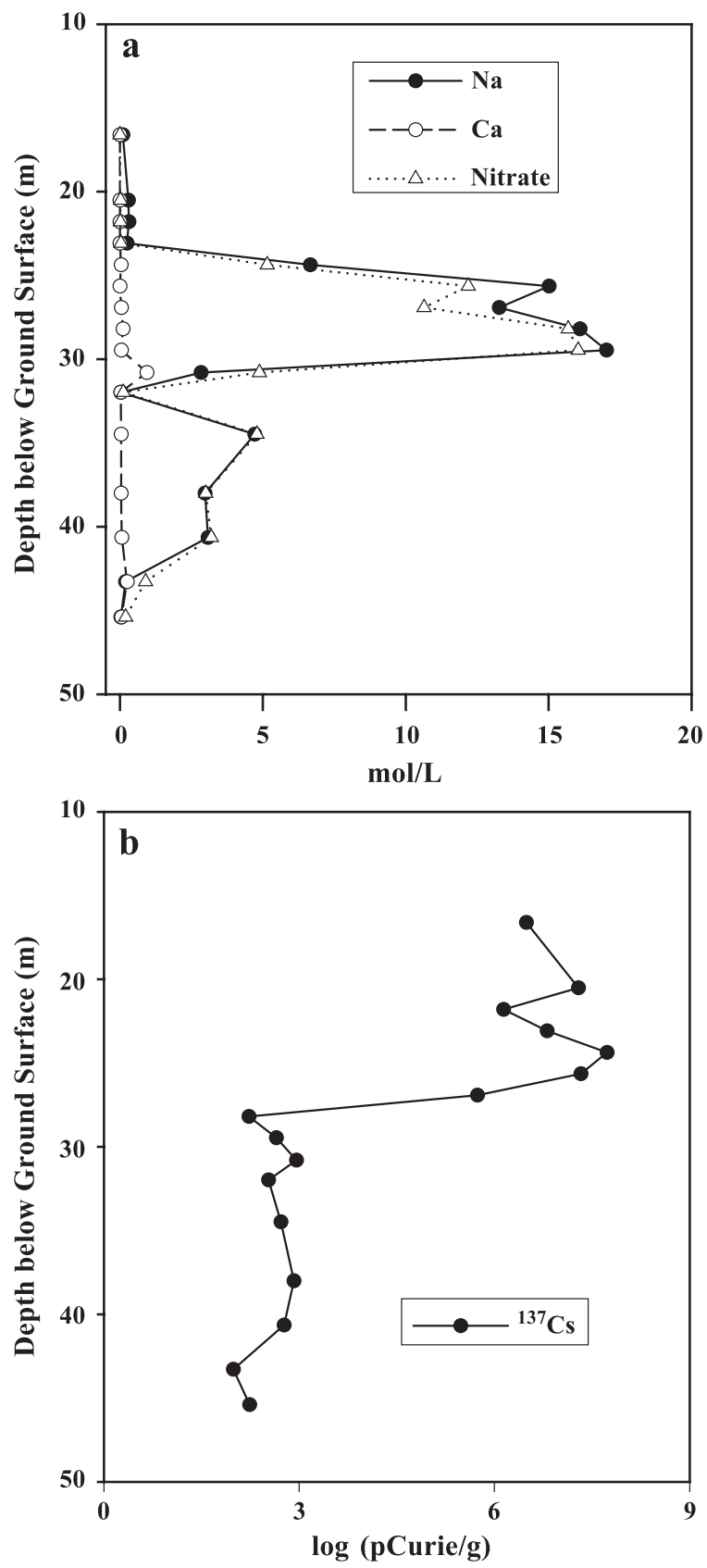

Fig. 6. (a) Measured porewater concentrations of $\mathrm{Na}^{+}, \mathrm{K}^{+}, \mathrm{Ca}^{2+}$, and $\mathrm{NO}_{3}^{-}$in sediments beneath leaked tank SX108 at Hanford. (b) Total ${ }^{137}$ Cs concentration in SX-108 sediments determined by gamma counting. 

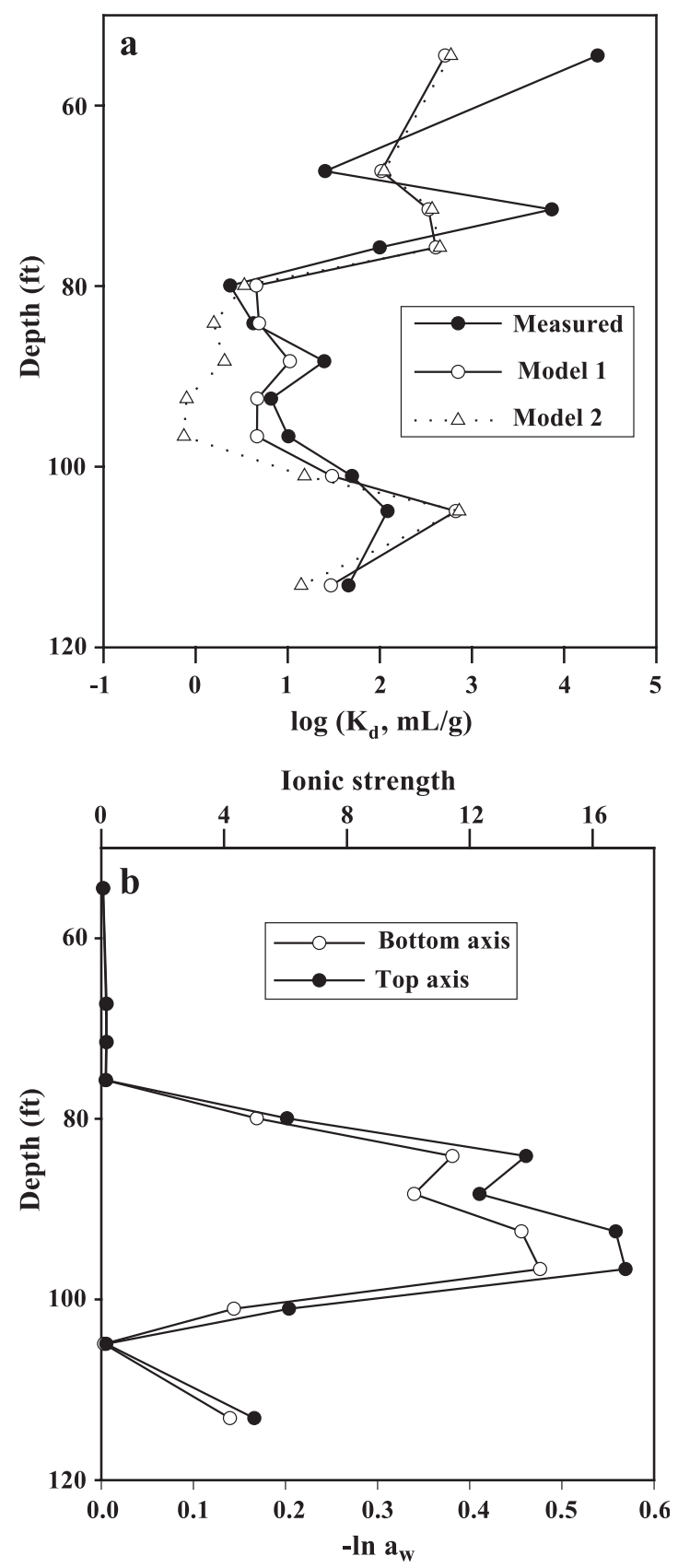

Fig. 7. Measured and predicted vertical profiles of ${ }^{137} \mathrm{Cs}-K_{\mathrm{d}}(\mathrm{a})$ and calculated vertical profiles of water activity and ionic strength (b) in ${ }^{137} \mathrm{Cs}^{+}$-contaminated sediments beneath leaked tank SX-108 at Hanford. 
Many factors may have caused the noted discrepancies between the model predictions and the experimental measurements of $K_{\mathrm{d}}$ (Fig. 7), but resolving the magnitude of their effect is difficult. The simulated environment beneath Tank 108 is a harsh and complex one. Down-hole measurements in a borehole near the location of the SX-108 core indicated that the in situ temperature at depths of 15 to $35 \mathrm{~m}$ ranged between 50 and $70{ }^{\circ} \mathrm{C}$, with a peak in temperature at depth of $23 \mathrm{~m}$. This residual thermal load results from waste-boiling in the tanks in the 1950s and 1960s that was driven by radioactive decay of short-lived isotopes. Our ion exchange measurements were made at $30{ }^{\circ} \mathrm{C}$, and no attempt was made to temperature-extrapolate our calculations of aqueous speciation or $K_{e x}$ to higher temperatures. We have, however, measured $\mathrm{Na}^{+}-\mathrm{Cs}^{+}$exchange isotherms at higher temperatures $\left(45\right.$ and $60{ }^{\circ} \mathrm{C}$ ) and observed relatively small enthalpy effects at low adsorption density (data not shown). The $K_{\mathrm{d}}$ and $K_{\mathrm{v}}$ for $\mathrm{Cs}^{+}$decrease at higher temperature (as compared to $30{ }^{\circ} \mathrm{C}$ ) as a result of the exchange enthalpy effect. While we state above that our calculations suggest that the in-ground Cs pool is in approximate exchange equilibrium, we have also noted in other soon to be published findings (Liu et al., 2003) that a fraction of the adsorbed ${ }^{137} \mathrm{Cs}^{+}$in these very same sediments is poorly exchangeable (30-40\%). Such incomplete exchangeability, as result of intraparticle diffusion and grain armoring by secondary precipitates, would increase the measured $K_{\mathrm{d}}$ over that predicted with an equilibrium model. This effect appears to be the primary cause of discrepancy. The effects of temperature and incomplete exchange may have been compounded at the shallow depths (e.g., 16-24 m) by significant mineral alteration (e.g., sorbent dissolution or precipitation) resulting from waste-sediment reaction (Liu et al., 2003). Electron microscopy of these sediments showed massive grain overgrowths by secondary aluminosilicate precipitates (Liu et al., 2003), some of which were zeolite-like in composition and morphology. In spite of these complications, however, we feel that our predictions of ${ }^{137} \mathrm{Cs}-K_{\mathrm{d}}$ near the core of the waste plume $(23-32 \mathrm{~m})$ are quite remarkable in their approximation of the field data.

The numeric analyses performed in this study were based on a generalized thermodynamic treatment of homovalent cation exchange using Gibbs-Duhem equation (Eq. (6)), which only considered exchangeable cationic species and solvent effects (Grant and Fletcher, 1993; Sposito, 1981). The ionic strength dependence of the selectivity coefficients was described solely as an effect of hydration energy and water activity. Other factors, such as anion and/or salt imbibement, however, could also affect the $\mathrm{Cs}^{+}$ selectivity coefficients. Salt imbibement appeared to be a negligible effect in the laboratory exchange experiments because the solubility of the electrolytes was much higher than the electrolyte concentrations used. Salt imbibement may be important in the field where $\mathrm{Na}$ concentrations reached up to $15 \mathrm{~mol} / \mathrm{l}$ at some locations. Anion imbibement would affect the chemical potential of the exchanger phase. Anion inclusion would increase the apparent cation exchange capacity to maintain charge neutrality. The selectivity coefficients, which were calculated with a fixed CEC, would therefore increase if anion inclusion was significant. Our noted increase in selectivity coefficient with ionic strength (Fig. 3) could be explained by anion imbibement, if its magnitude increased with the ionic strength. The fact that greater ionic strength effects were observed for $\mathrm{Cs}^{+}-\mathrm{Na}^{+}$exchange than $\mathrm{Cs}^{+}-\mathrm{K}^{+}$exchange, however, argues against anion imbibement. The small effects of ionic strength on the exchange of $\mathrm{Cs}^{+}-\mathrm{Ca}^{2+}$ (Brouwer 
et al., 1983; Zachara et al., 2002); and $\mathrm{Cs}^{+}-\mathrm{Sr}^{2+}$ and $\mathrm{Cs}^{+}-\mathrm{Ba}^{2+}$ (Brouwer et al., 1983) also support this conclusion.

\section{Conclusions}

The ion exchange behavior of $\mathrm{Cs}^{+}$in high concentration $\mathrm{Na}^{+}$and $\mathrm{K}^{+}$electrolytes $(1-5$ mol/l) was studied to provide insights on the sorptive retardation of ${ }^{137} \mathrm{Cs}^{+}$from high level nuclear wastes (HLW) released to the vadose zone at the U.S. Department of Energy Hanford site. At Hanford, over 1 million gallon of saline caustic HLW has leaked to the vadose zone from aging single shell storage tanks, and considerable concern exists over the subsurface migration of radioactive and chemical contaminants in these materials. Cesium-137 is the radioactive constituent with the highest activity in the HLW, and expedited migration of ${ }^{137} \mathrm{Cs}^{+}$has been observed beneath certain tanks.

The ion exchange behavior of $\mathrm{Cs}^{+}$on Hanford sediment was significantly influenced by electrolyte concentration. The cation exchange capacity (CEC, resulting from micas and smectite) of the sediment was low $(82.5 \mu \mathrm{eq} / \mathrm{g})$, but sufficient to induce high sorption capacity for radiocesium. The Vanselow selectivity coefficient $\left(\mathrm{K}_{\mathrm{v}}\right)$ increased with increasing ionic strength in both $\mathrm{Na}^{+}$and $\mathrm{K}^{+}$electrolytes. The ionic strength effect was greater for the exchange of $\mathrm{Na}^{+}-\mathrm{Cs}^{+}$than for $\mathrm{K}^{+}-\mathrm{Cs}^{+}$, an observation consistent with the hydration energies of the exchanging cations. A two-site ideal ion exchange model was modified to include a water activity term for the exchanger phase through application of the Gibbs-Duhem equation. This modified two-site model well described the electrolyte concentration effect on binary, homovalent $\mathrm{Cs}^{+}$exchange in $\mathrm{Na}^{+}$and $\mathrm{K}^{+}$electrolytes.

The "water activity-corrected model" yielded better predictions of in situ ${ }^{137} \mathrm{Cs}^{+} K_{\mathrm{d}}$ values in a HLW-contaminated borehole than a comparable model without such correction. The porewater concentrations of $\mathrm{NaNO}_{3}$ exceeded $15 \mathrm{~mol} / \mathrm{l}$ in the core of the HLW, vadose zone plume. These salt concentrations significantly depressed water activity. The two-site water activity-corrected model embodies the minimum phenomenology needed to describe the ion exchange retardation of ${ }^{137} \mathrm{Cs}^{+}$from the HLW brines that characterizes much of the stored waste at the Hanford site. Our geochemical model provides a basis to forecast the sorptive retardation ${ }^{137} \mathrm{Cs}^{+}$beneath the many leaked tanks where funds are not available for subsurface sampling and analyses, and it is now being used for that purpose.

\section{Acknowledgements}

Research was supported by the U.S. Department of Energy (DOE) through the Environmental Management Sciences Program (EMSP) and the Hanford Science and Technology Program managed by the Groundwater/Vadose Zone Integration Project. Pacific Northwest National Laboratory (PNNL) is operated for the DOE by Battelle Memorial Institute under Contract DE-AC06-76RLO 1830. We appreciated Dr. Andrew Felmy at PNNL for providing GMIN code and his constructive discussion on its application to the ion exchange data. We thank Drs. C. Poinssot, M. Schlegel, and M. H. Bradbury for their comments and suggestions. 


\section{References}

Barrer, R.M., Klinowski, J., 1974. Ion-exchange selectivity and electrolyte concentration. J. Chem. Soc., Faraday Trans. I 70, 2080-2091.

Bradbury, M.H., Baeyens, B., 2000. A generalised sorption model for the concentration dependent uptake of caesium by argillaceous rocks. Contam. Hydrol. 42, 141-163.

Brouwer, E., Baeyens, B., Maes, A., Cremers, A., 1983. Cesium and rubidium ion equilibria in illite clay. J. Phys. Chem. 87, 1213-1219.

Comans, R.N.J., Haller, M., De Preter, P., 1991. Sorption of cesium on illite: non-equilibrium behaviour and reversibility. Geochim. Cosmochim. Acta 55, 433-440.

Cornell, R.M., 1993. Adsorption of cesium on minerals: a review. J. Radioanal. Nucl. Chem., Articles 171, $483-500$.

Cremers, A., Elsen, A., De Preter, P., Maes, A., 1988. Quantitative analysis of radiocaesium retention in soils. Lett. Nat. 335, 247-249.

Eberl, D.D., 1980. Alkali cation selectivity and fixation by clay minerals. Clays and Clay Minerals 28, $161-172$.

Elprince, A.M., Babcock, K.L., 1975. Prediction of ion-exchange equilibrium in aqueous systems with more than two counter-ions. Soil Science 120, 332-338.

Felmy, A.R., 1995. GMIN, a computerized chemical equilibrium program using a constrained minimization of the Gbbs free energy: summary report. In: Loeppert, R.H., Schwab, A.P., Goldberg, S. (Eds.), Chemical Equilibrium and Reaction Models Soil Science Society of America, Madison, WI, USA.

Fletcher, P., Townsend, R., 1981. Ternary ion exchange in zeolites. Journal of the Chemical Society. Faraday Transactions 2 77, 955-963.

Gaines, G.L., Thomas, H.C., 1953. Adsorption studies on clay minerals: II. A formulation of the thermodynamics of exchange adsorption. Journal of Chemical Physics 21, 714-718.

Grant, S.A., Fletcher, P., 1993. Chemical thermodynamics of cation exchange reactions. Ion Exchange and Solvent Extraction 11, 1-108.

Jones, T.E., Watrous, R.A., Maclean, G.T., 2000. Inventory Estimates for Single-Shell Tank Leaks in S and SX Tank Farms. RPP-6285, Rev. 0.

Lichtner, P.C., 2001. Estimating Tank Supernatant Liquid Compositions. Los Alamos National Laboratory, Los Alamos, NM LA-UR-01-1403.

Liu, C., Zachara, J.M., Smith, S.C., McKinley, J.P., Ainsworth, C.C., 2003. Desorption kinetics of radiocesium from the subsurface sediments at Hanford site, USA. Geochimica et Cosmochimica Acta 67, 2893-2912.

Pitzer, K.S., 1994. Ion Interaction Approach: Theory and Data Correlation. Activity Coefficients in Electrolyte Solutions CRC Press, Boca Raton, FL, USA.

Poinssot, C., Baeyens, B., Bradbury, M.H., 1999. Experimental and modeling studies of caesium sorption on illite. Geochimica et Cosmochimica Acta 63, 3217-3227.

Sawhney, B.L., 1972. Selective sorption and fixation of cations by clay minerals: a review. Clays and Clay Minerals 20, 93-100.

Serne, R.J., Schaef, H.T., Last, G.V., Lanigan, D.C., Lindenmeier, C.W., Clayton, R.E., LeGore, V.L., O’Hara, M.J., Brown, C.F., Orr, R.D., Kutnyakov, I.V., Wilson, T.C., Burke, D.B., Williams, B.A., Bjornstad, B.N., 2001. Geologic and Geochemical Data Collected from Vadose Zone Sediments from the Slant Borehole Under SX-108 in the S/SX Waste Management Area and Preliminary Interpretations. Pacific Northwest National Lab, Richland, WA PNNL-2001-4.

Sposito, G., 1981. The Thermodynamics of Soil Solutions Oxford Clarendon Press, New York, USA.

Wilson, G.M., 1964. Vapour-liquid equilibrium: XI. A new expression for the excess energy of mixing. American Chemical Society Jounal 86, $127-130$.

Zachara, J.M., Smith, S.C., Liu, C., McKinley, J.P., Serne, R.J., Gassman, P.L., 2002. Sorption of Cs ${ }^{+}$to micaceous subsurface sediments from the Hanford site, USA. Geochimica et Cosmochimica Acta 66, $193-211$ 